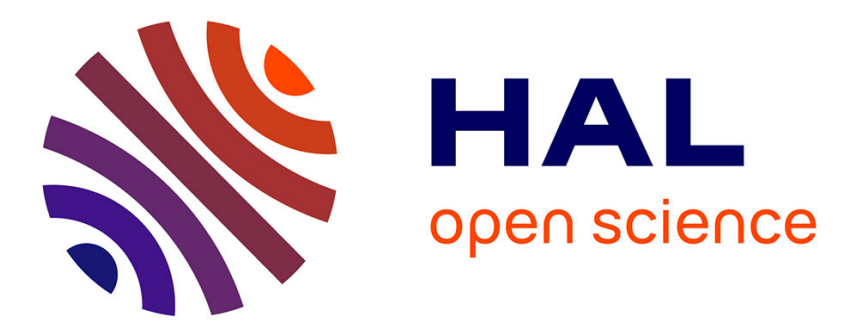

\title{
Experiments, numerical models and optimization of carbon-epoxy plates damped by a frequency-dependent interleaved viscoelastic layer
}

Rémy Mateu Pastor, Hervé Le Sourne, Eric Le Gal La Salle, Patrice Cartraud

\section{- To cite this version:}

Rémy Mateu Pastor, Hervé Le Sourne, Eric Le Gal La Salle, Patrice Cartraud. Experiments, numerical models and optimization of carbon-epoxy plates damped by a frequency-dependent interleaved viscoelastic layer. Mechanics of Advanced Materials and Structures, 2021, pp.1-19. 10.1080/15376494.2021.1882626 . hal-03155700

\author{
HAL Id: hal-03155700 \\ https://hal.science/hal-03155700
}

Submitted on 6 Apr 2021

HAL is a multi-disciplinary open access archive for the deposit and dissemination of scientific research documents, whether they are published or not. The documents may come from teaching and research institutions in France or abroad, or from public or private research centers.
L'archive ouverte pluridisciplinaire HAL, est destinée au dépôt et à la diffusion de documents scientifiques de niveau recherche, publiés ou non, émanant des établissements d'enseignement et de recherche français ou étrangers, des laboratoires publics ou privés. 


\title{
Experiments, numerical models and optimization of carbon-epoxy plates damped by a frequency-dependent interleaved viscoelastic layer
}

\author{
R. Mateu Pastor ${ }^{a, b, c}$, H. Le Sourne ${ }^{a, b}$, E. Le Gal La Salle ${ }^{a, d}$, and P. Cartraud $d^{b, c}$ \\ ${ }^{a}$ ICAM Nantes, Nantes, France; ${ }^{b}$ GeM Institute (UMR CNRS 6183), Nantes, France; ${ }^{c}$ Ecole Centrale de Nantes, Nantes, France; ${ }^{d}$ LTeN Institute \\ (UMR CNRS 6607), Nantes, France
}

\begin{abstract}
The research work presented in this paper aims to optimize the dynamic response of a carbon-epoxy plate by including into the laminate one frequency-dependent interleaved viscoelastic layer. To keep an acceptable bending stiffness, some holes are created in the viscoelastic layer, thus facilitating the resin through layer penetration during the co-curing manufacturing process. Plates including (or not) one perforated (or non-perforated) viscoelastic layer are manufactured and investigated experimentally and numerically. First, static and dynamic tests are performed on sandwich coupons to characterize the stiffness and damping properties of the plates in a given frequency range. Resulting mechanical properties are then used to setup a finite element model and simulate the plate dynamic response. In parallel, frequency response measurements are car-ried out on the manufactured plates, then successfully confronted to the numerical results. Finally, a design of experiments is built based on a limited number on numerical simulations to find the configuration of bridges that maximizes the damping while keeping a stiffness higher than half the stiffness of the equivalent undamped plate.
\end{abstract}

\section{Introduction}

Recent research on materials has focused on adding new functionalities to composite structures, mixing for example composite and viscoelastic materials. As a result, such multifunctional composites are nowadays used for specific purposes like damping or reducing acoustic emissions, which were not initially the aim of those materials.

One of the first experimental works on constrained viscoelastic composite laminates was performed in 1959 by Ungar et al. [1], who characterized the influence of several parameters like damping factor, thickness and number of viscoelastic layers constrained between aluminum plates. It was shown that adding damping functionalities always affects the stiffness properties of the composite. Indeed, as demonstrated by Liao et al. [2], inserting a viscoelastic layer into the laminate may cause both delamination and important loss of bending stiffness. One solution to overcome this problem consisted in perforating the viscoelastic layer(s), allowing matrix polymer to get through the resulting holes during the curing process.

Using the vacuum assisted resin transfer molding process, Robinson and Kosmatka [3] manufactured similar sandwich plates with the objective to control the damping to stiffness ratio. The authors observed that maintaining a contact between the rubber and the laminate equal or higher than $95 \%$ multiplies by up to 14 times the loss factor but, at the same time, decreases the bending stiffness by up to $60 \%$.
Moreover, keeping a contact surface equal to $95 \%$, a decrease of the hole size and distance between holes allows to increase the plate rigidity. In the same way, Pan and Zhang [4] worked on 5 composite laminate plates, all with an embedded NBR rubber layer but with different hole sizes. They demonstrated that when the rubber perforated area exceeds $7 \%$ of the plate surface, the bending stiffness becomes similar to the undamped plate but the loss factor remains small.

In another paper [5], the same authors measured both the loss factor and Young modulus of the plate using dynamic mechanical thermal analysis (DMTA). Applying a $1 \mathrm{~Hz}$ constant excitation, they observed that damping factor increases with temperature from -60 to $-7^{\circ} \mathrm{C}$, then decreases from -7 to $100^{\circ} \mathrm{C}$, the maximum value occurring during the viscous state. Moreover, the Young modulus was shown to decrease slowly in glassy state, faster in viscous state and slowly again in elastomeric state.

More recently, Hujare and Sahasrabudhe [6] also showed that inserting viscoelastic materials in a 3D sandwich beam structure allows to increase the damping factor. They compared different viscoelastic materials in medium frequency range and found that nitrile, SBR, urethane and butyl materials better damp vibrations of such beam than PMMA, polyethylene, and polypropylene.

Several authors like Moreira and Rodrigues [7], Vasques and Cardoso [8] reviewed the different theories and approaches to model the dynamic response of such damped 


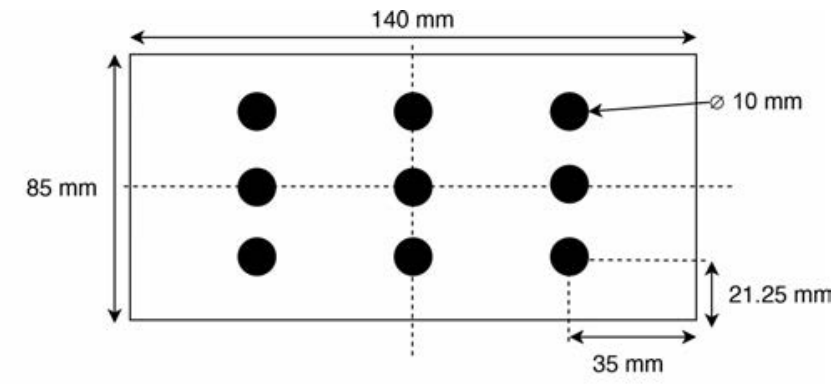

5 to $6 \mathrm{~mm} \uparrow$

Figure 1. Specimen dimensions.

sandwich plates. 3D solid models were compared to less time consuming 2D shell models and different approaches to account for the damping of such structures were confronted. Saravanos and Chamis [9] worked on modeling composite and metallic laminates damped with interlaminar viscoelastic layers. Using the so-called discrete layer laminate damping theory, they compared different arrangements for composite and aluminum constraining materials. They showed that composite-based sandwiches with strong anisotropy variations have potentially higher damping properties than geometrically equivalent ones based on aluminum skins. Wan et al. [10] used the transfer matrix method to assess modal and damping characteristics of a multilayered constrained plate. Varying both the number and the thickness of the viscoelastic layers as well as their arrangement, they demonstrated that multilayer structures achieve better damping when the number of viscoelastic layers increases but, beyond a certain number of layers, the loss factor does not vary significantly anymore. In addition, symmetrical structures were shown to offer a better loss factor than non symmetric ones.

More recently, $\mathrm{Xu}$ et al. [11] presented a multi-objective optimization of composite laminates including viscoelastic layers. Using layer-wise finite element method, they maximized the modal damping while minimizing at the same time the structural mass. Frequency-dependent viscoelastic material properties were considered in their study. As a first step, they investigated a symmetrically hybrid composite laminated plate with two interleaved viscoelastic layers inserted in different positions. They observed that these latter offer better damping properties when inserted at mid-plane.

Finally, Zhai et al. [12] used the Navier solution based on first-order shear deformation theory with the objective to maximize the damping level by varying the plate aspect ratio as well as the ratio between composite and viscoelastic layer thicknesses. They found that a square plate offers the highest loss factor and when the ratio between the plate dimensions and thickness increases, the loss factor decreases.

Some analytical developments were performed to analyze the behavior of composite beams and plates with soft core layer. Berthelot [13] modeled beams and plates using first order shear deformation theory (FSDT). However, when the stiffness of the core differs sensitively from the skins, the accuracy of such approach is not sufficient and layer-wise or
Zig-Zag theories seem to be more suitable. Carrera [14] and more recently $\mathrm{Hu}$ et al. [15] reviewed theories for beams and plates from basic theories as classical laminate theory to more complex as Zig-Zag and layer-wise theory. Koutsawa and Daya [16] used layer-wise theory to model a glass beam including a polyvinylbutane (PVB) layer and more recently Schulze et al. [17] compared FSDT and layer-wise theories with different materials properties and different skin to core thickness ratios. They found that although FSDT and layerwise theory results converge for certain skin to core stiffness ratios, the layer-wise theory keeps the more accurate in all cases. The same conclusion was obtained by Naumenko and Eremeyev [18] for a photovoltaic plate considered as a composite structure with a soft core. One can also build a model, derived from the asymptotic expansion approach, to describe the overall plate behavior, and accounting for the stiffness constrast between the core and the skins [19].

Most of the above research works are based on either experimental, analytical or numerical approach but very few published works include both experimental and numerical analyses. In the present study, static and dynamic experimental analyses of carbon-epoxy plates that include (or not) a perforated (or non perforated) viscoelastic layer are carried out and compared with finite element simulations. In a first step, the static and dynamic mechanical properties of the plate constitutive materials are measured and used to set-up the finite element models. A special attention is paid on measuring and modeling accurately the variation of both the shear modulus and the loss factor with the excitation frequency. In a second step, the finite element models are validated by comparing the dynamic response of damped and undamped plates post-processed from the simulations to experimental results. In a third step, not only the influence of the viscoelastic film but also the influence of the bridges created between the upper and lower carbon-epoxy skins on the plate accelerance are investigated. Finally, the numerical models are used to set a design of experiments, which allows to find the best location and size of the resin bridges that maximizes the damping of the plates while keeping an acceptable bending stiffness.

\section{Experimental procedure}

\subsection{Plate particulars}

As shown in Figure 1, $140 \times 85 \mathrm{~mm}$ plate specimens were manufactured, keeping the same layup for the laminate but inserting, or not, a $1 \mathrm{~mm}$-thick viscoelastic DYAD layer at mid-thickness. For some specimens, this layer was perforated before laying-up with 9 holes equally distributed over its surface. Resulting stacking sequences are presented in Table 1 for carbon-epoxy and carbon-epoxyDYAD specimens.

As the prepreg carbon is manually applied in several layers, some imperfections occur regarding the thickness of the manufactured plates so length, width and thickness are accurately measured with a $10^{-2} \mathrm{~mm}$ precision tool. As highlighted in Figure 2 for a carbon-epoxy plate, both the measured dimensions and thickness distribution are then 


\begin{tabular}{llr}
\hline Set o f plates & Stacking sequence & Theoretical thickness $[\mathrm{mm}]$ \\
\hline Set 1 - Carbon-epoxy & {$\left[0,90_{2}, 0\right]_{S}$} & 5 \\
Set 2 - Carbon-epoxy with DYAD & {$\left[0,90_{2}, 0, \text { DYAD601 }\right]_{S}$} & 6 \\
Set 3 - Carbon-epoxy with perforated DYAD & {$\left[0,90_{2}, 0, \text { DYAD601 }\right]_{S}$} & 6 \\
\hline
\end{tabular}

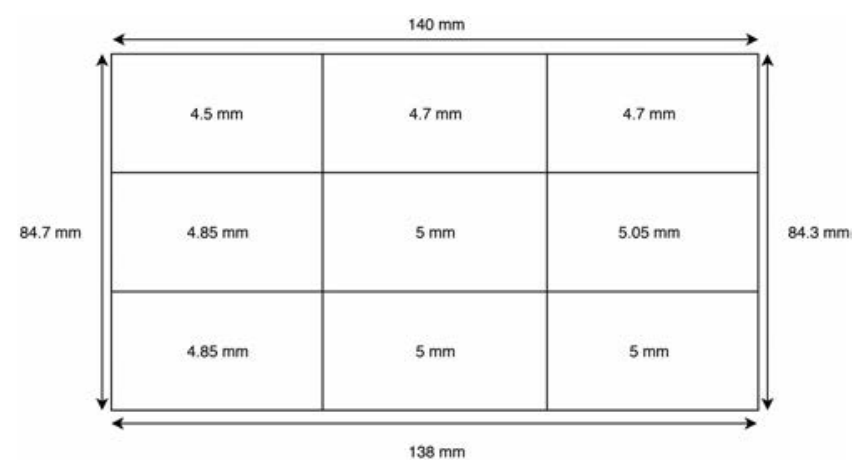

Figure 2. Carbon epoxy sample dimensions.

registered for each plate assuming a piecewise constant thickness and used as input for the numerical model.

\subsection{Material specification}

Prepreg carbon-epoxy (with and without viscoelastic layer) lay-ups are first built with two fiber orientations $\left(0^{\circ}, 90^{\circ}\right)$ when draping the different plies. During the manufacturing process, the extraction of air bubbles is performed every four plies then co-curing is processed during 3 hours at $120^{\circ} \mathrm{C}$. All the plates are manufactured using HexPly[textregistered] UD pre-preg carbon-epoxy M79/35\%/UD6000/CHS.

Three different sets of plates are manufactured inserting (or not) one $1 \mathrm{~mm}$-thick layer of DYAD 601[textregistered] SoundcoatTM viscoelastic material inside the laminate and creating (or not) some holes in the viscoelastic film before laying-up:

- The first set of plates is made using only carbon-epoxy plies. Resulting plates are expected to have the highest stiffness but, at the same time, the lowest damping characteristics.

- In the second set of plates, the carbone-epoxy laminate includes one constrained viscoelastic layer. It is expected to have the highest loss factor but at the same time the lowest bending stiffness.

- In the third set, the laminate includes one viscoelastic layer but 9 holes (diameter $=10 \mathrm{~mm}$ ) have been cut in the film. During co-curing, the resin is supposed to flow through the holes, creating 9 "bridges" between the upper and lower carbon-epoxy skins. Note that the holes, which spatial distribution is shown in Figure 1, represent $6 \%$ of the plate surface.

Elastic properties of carbon-epoxy plies listed in Table 2 are retrieved from reference [20]. Then, some of these values will be slightly modified in order to match with the threepoints bending tests performed by the authors, as will be explained later. The density is extracted from sample weight

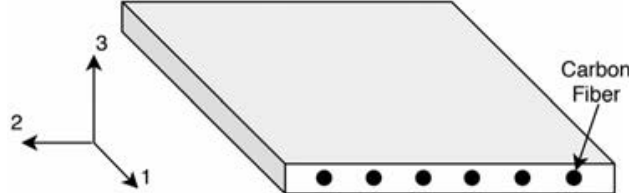

Figure 3. Properties directions.

measurements and the loss factor is adjusted by confronting forced response tests with finite element simulations.

The DYAD static properties, i.e. its density $\rho$, shear modulus $G$ and bulk modulus $B$ are extracted from the manufacturer's data. As the deformations of the viscoelastic layer is expected to remain small, a Neo-Hookean viscohyperelastic behavior law is considered for the numerical simulations, which parameters are presented in Table 3.

The material is assumed here to be incompressible. In this case, the strain energy per unit of reference volume $U$ is related to the first deviatoric strain invariant by the following expression:

$$
U=C_{10}\left(I_{1}-3\right)
$$

In the relation above, $I_{1}$ is the trace of the right Cauchy Green deformation tensor:

$$
I_{1}=\lambda_{1}^{2}+\lambda_{2}^{2}+\lambda_{3}^{2}
$$

Where $\lambda_{i}$ are the principal stretches.

\subsection{Three-point bending measurement bench}

As aforementioned, in order to adjust the mechanical characteristics of both the carbon-epoxy laminate and carbonepoxy-DYAD sandwich for the simulations, three-points bending quasi-static tests are performed on an Instron 5566A bench (Figure 4(a)). For the three samples tested for each set of plates, a vertical displacement varying from 0 to $0.6 \mathrm{~mm}$ is applied at mid-span and the resulting resistant vertical force is measured.

\subsection{Dynamic measurement analysis bench}

It is well known that both the stiffness and damping factor of a viscoelastic rubber-like material may vary significantly with the frequency of the excitation (Snowdon [21]). That is why Dynamical Mechanical Analysis (DMA) tests are performed on 4 DYAD601 coupons at different temperatures. Figure 4(b) shows the Metravib DMA bench used for these measurements. The related parameters are the following ones:

- Dynamic deflection amplitude: $0.175 \mathrm{~mm}$

- 1 to $100 \mathrm{~Hz}$ frequency range with 20 logarithmic steps

- Temperatures tested: $24,18,14^{\circ} \mathrm{C}$ 
Shear deformation is dynamically applied to the coupons and the complex shear modulus and damping loss factor are measured at three different temperatures. Then, the WLF method developed by Williams et al. [22] and Ferry [23] is applied to extrapolate the measurements up to $2000 \mathrm{~Hz}$. The frequency evolutions of the storage modulus $G^{\prime}$ and loss modulus $G^{\prime \prime}$ are plotted in Figure 5. It may be observed that both $G^{\prime}$ and $G^{\prime \prime}$ seem to reach a maximum value (around $1.4 \mathrm{GPa}$ ) at $2000 \mathrm{~Hz}$.

\subsection{Dynamic forced response bench}

An instrumented test bench is set-up to measure the frequency response of the different manufactured plates when they are subjected to a sinusoidal excitation.

Table 2. Carbon-epoxy properties (the 3 axes are defined in Figure 3).

\begin{tabular}{lccccccc}
\hline $\mathrm{E}_{11}[\mathrm{MPa}]$ & $\begin{array}{c}\mathrm{E}_{22}=\mathrm{E}_{33} \\
{[\mathrm{MPa}]}\end{array}$ & $\begin{array}{c}\mathrm{G}_{12}=\mathrm{G}_{13} \\
{[\mathrm{MPa}]}\end{array}$ & $\begin{array}{c}\mathrm{G}_{23} \\
{[\mathrm{MPa}]}\end{array}$ & $\nu_{12}=\nu_{13}$ & $\nu_{23}$ & {$\left[\mathrm{~T} / \mathrm{mm}^{3}\right]$} & $\tan \delta$ \\
\hline 100000 & 8110 & 4650 & 5000 & 0.3 & 0.4 & $1.4 \mathrm{E}-9$ & 0.018 \\
\hline
\end{tabular}

Table 3. DYAD601 properties.

\begin{tabular}{lc}
\hline$C_{10}=G / 2[\mathrm{MPa}]$ & $\rho\left[\mathrm{T} / \mathrm{mm}^{3}\right]$ \\
\hline 0.2 & $1.3 \mathrm{E}-9$ \\
\hline
\end{tabular}

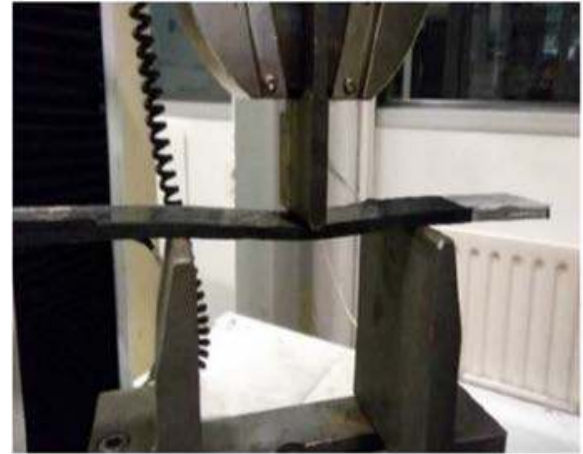

(a) Three-points bending bench
Recommendations found in the book of Ewins [24] are followed to choose and position the different components of the bench such as the exciter, the transducer, the force sensor, the accelerometer, etc. As represented in Figure 6, the plates are suspended to a rigid frame using nylon threads. In order to excite the first bending mode of the plate, a shaker fixed to a rigid structure and controlled by a frequency generator is used to apply a sinusoidal displacement at the plate center. The acceleration is then measured at the same location using a PCB sensor (353 B17) bounded on the other side of the plate.

To measure the load applied by the shaker, a PCB force sensor (208 C02) is inserted between the shaker and the plate. A $60 \mathrm{~mm}$-long rod with a $4 \mathrm{~mm}$ diameter is used to connect the shaker to the plate center. An overview of the bench is shown in Figure 6 .

\section{Numerical modeling}

For the three different sets of plates, static and forced dynamic response finite element analyses are then performed using the commercial code ABAQUS. By applying a given static or dynamic load at the center of the plates, the mechanical responses in term of static deflection or acceleration are post-processed.

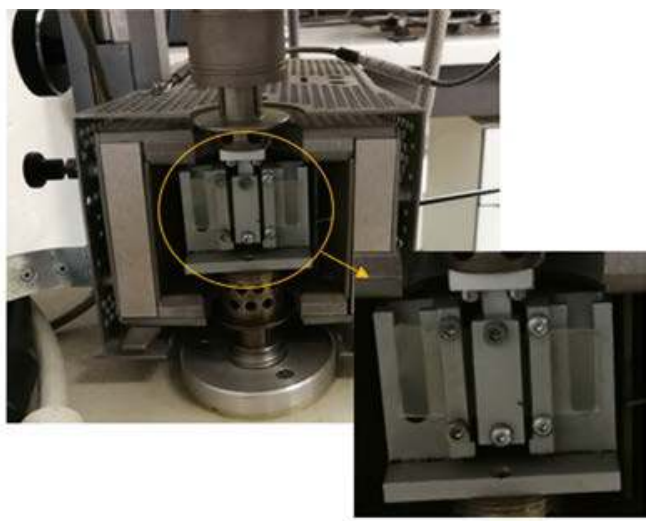

(b) Metravib DMA Bench

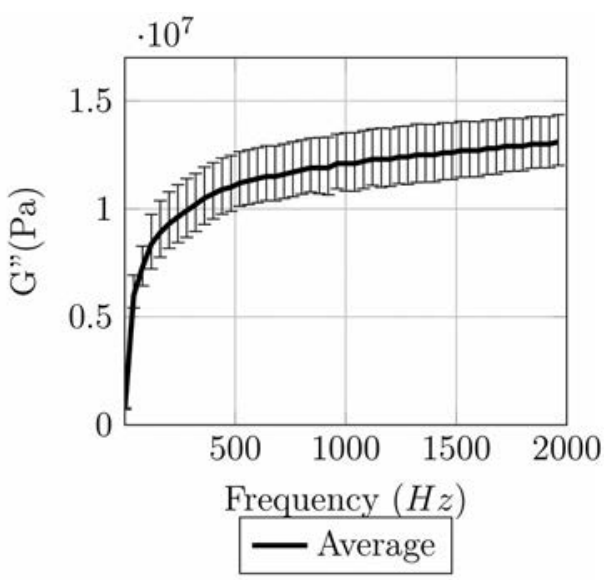

(b) Shear loss modulus

Figure 5. Frequency evolution of shear storage and loss modulii. 


\subsection{Finite element models}

As the first set is concerned, carbon-epoxy plates are meshed using 4-nodes reduced integrated shell (S4R) elements based on Koiter-Sanders formulation [25]. For the second and third sets of plates, carbon-epoxy skins are also meshed using S4R elements but 8 -nodes hybrid reduced integrated solids (C3D8RH) elements are chosen for the viscoelastic layer (see Figure 7). As the shell nodes are coincident with the nodes of the outer faces of the solid mesh, it is assumed that carbonepoxy skins are perfectly bonded to the DYAD layer. The resin bridges created through the viscoelastic layer of the third set plates are explicitly modeled using C3D8RH solid elements and mechanical characteristics of the epoxy resin listed in Table 4 are assigned to the corresponding elements.

\subsection{Loading and boundary conditions}

The loading conditions are slightly different in the static and dynamic experimental tests: in the three-points bending

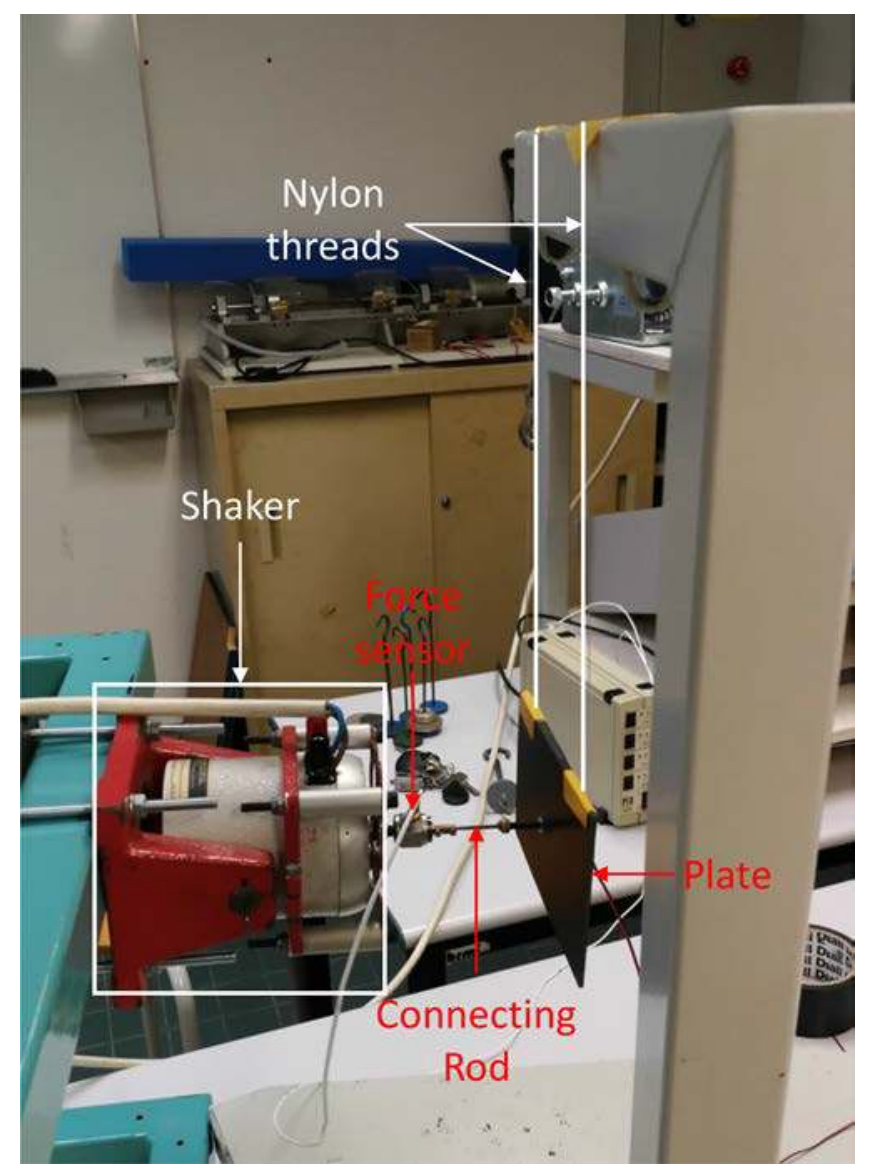

Figure 6. Forced response analysis bench. tests, the load is distributed over a $0.75 \mathrm{~mm}$-width band located at mid-span of the plate while for the frequency response analyses, the sinusoidal load exerted by the shaker is distributed over a small squared surface located at the plate center.

To simulate both the static and dynamic response tests, only a quarter of the plate is modeled and symmetry conditions are applied on the nodes located in the two symmetry planes.

In the static test, the plate is assumed to be simply supported near two opposite edges and the corresponding symmetrical finite element model is presented in Figure 8. In order to represent the test loading conditions, three different static forces are distributed over a $0.75 \mathrm{~mm}$-width band located at mid-plate (see Figure 8).

Regarding the frequency response analyses, the plates are supposed to be completely free. As aforementioned, only a quarter plate is modeled and symmetry boundary conditions are applied to the relevant nodes. In order to represent one quarter of the rod and sensor mass that is captured by the force sensor, lumped masses (8.5 grams) are distributed on some nodes located at the plate center. Then, a uniform pressure with a sinusoidal time-dependence is applied over a $16 \mathrm{~mm}^{2}$ centered squared surface, i.e. the surface that has been actually loaded during the dynamic tests.

\subsection{Direct solution approach}

Numerical frequency response analyses are performed for the three different sets of plates using ABAQUS software. With the objective to account for the frequency dependent properties of the viscoelastic material, the direct solution approach is considered for the numerical solution as suggested by Vasques [8] and used by Myklestad [26], Snowdon [21] and Beth [27]. In such approach, the following matrix equation is solved varying the frequency $f$ between $500 \mathrm{~Hz}$ and 1400 or $1700 \mathrm{~Hz}$ with a frequency step of $5 \mathrm{~Hz}$ to observe mainly the response related to the first bending mode of the plates:

$$
\left[\begin{array}{cc}
\mathfrak{R}(D(\omega)) & \mathfrak{I}(D(\omega)) \\
\mathfrak{I}(D(\omega)) & -\mathfrak{R}(D(\omega))
\end{array}\right]\left\{\begin{array}{c}
\mathfrak{R}[u(\omega)] \\
\mathfrak{I}[u(\omega)]
\end{array}\right\}=\left\{\begin{array}{c}
\mathfrak{R}[F(\omega)] \\
-\mathfrak{J}[F(\omega)]
\end{array}\right\}
$$

Where $\mathrm{u}(\omega)$ is the unknown complex displacement vector, $F(\omega)$ is the complex applied sinusoidal load. $\mathfrak{R}(D(\omega))$ and $\mathfrak{J}(D(\omega))$ are respectively the real and imaginary parts of the so-called dynamic stiffness matrix $D(\omega)$, defined as:

$$
\mathfrak{R}(D)=K-\omega^{2} M \quad \mathfrak{I}(D)=-C_{\tan \delta(\omega)}
$$

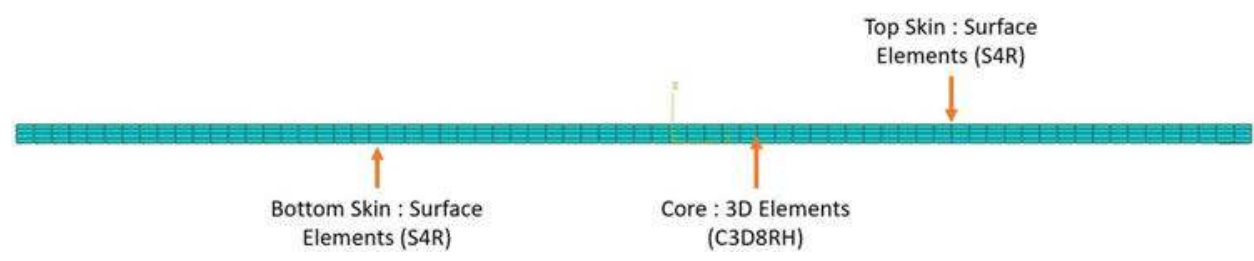

Figure 7. Finite elements used for carbon-epoxy-DYAD sandwich plate modeling. 
Table 4. Epoxy mechanical properties.

\begin{tabular}{lccc}
\hline Elastic modulus $[\mathrm{MPa}]$ & $\nu$ & $\rho\left[T / \mathrm{mm}^{3}\right]$ & $\tan \delta$ \\
\hline 2400 & 0.38 & $1.11 \mathrm{E}-9$ & 0.018 \\
\hline
\end{tabular}

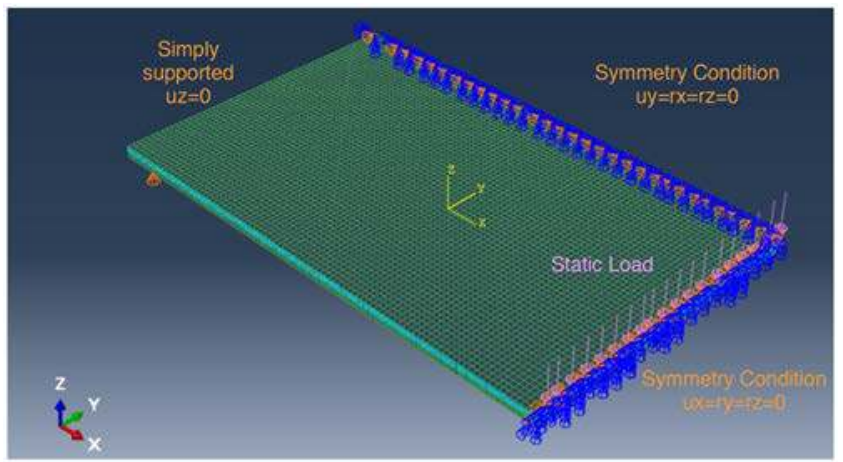

Figure 8. Boundary and loading conditions for numerical static analysis.

Where $K$ is the stiffness matrix, $\omega=2 \pi f$ is the circular frequency, $M$ is the structural mass matrix and $\mathrm{C}_{\tan \delta}(\omega)$ is the stiffness proportional structural damping matrix. It may be expressed as:

$$
C_{\tan \delta}(\omega)=\tan \delta(\omega) * K
$$

Where $\tan \delta(\omega)$ is the loss factor which characterizes the structural damping of the material.

In parallel, thanks to the test bench presented in subsection 2.5, forced response measurements are performed between 500 to $1700 \mathrm{~Hz}$ for the first set of plates and between 500 to $1400 \mathrm{~Hz}$ for the second and third sets.

To compare numerical and experimental results, the acceleration at the plate center is post-processed and the accelerance is determined at each circular frequency as:

$$
A(\omega)=\left|\frac{a(\omega)}{F(\omega)}\right| ; \quad a(\omega)=-\omega^{2} u(\omega)
$$

Where $a(\omega)$ is the acceleration post-processed at the plate center (at the position of the accelerometer) and $F(\omega)$ is the magnitude of the applied sinusoidal force. The gain of accelerance may then be calculated as:

$$
G_{d B}=20 \cdot \log _{10}\left(\left|\frac{a(\omega)}{F(\omega)}\right|\right)
$$

\subsection{Mesh size sensitivity analysis}

Element size varying from $0.66 \mathrm{~mm}$ to $4 \mathrm{~mm}$ for quadrilateral (square) elements and varying from $0.66 \times 0.17 \mathrm{~mm}$ to $4 \times 1 \mathrm{~mm}$ for hexahedral (cubic) elements are considered in the numerical mesh sensitivity analysis. The plate static stiffness and the gain of accelerance obtained for the different mesh sizes are compared in Table 5 and Figure 9, respectively.

It may be observed that both the stiffness and the dynamic response are not sensitive to the considered mesh sizes. In fact, even the coarser mesh is fine enough for effectively capturing the bending deformation of the plate as well as the shear deformation of the core layer. In order to
Table 5. Mesh sizes.

\begin{tabular}{lc}
\hline Mesh size $[\mathrm{mm}]$ & $K[\mathrm{~N} / \mathrm{mm}]$ \\
\hline $0.66 \times 0.17$ & 405 \\
$0.75 \times 0.25$ & 405 \\
$1.32 \times 0.33$ & 405 \\
$4 \times 1$ & 405 \\
\hline
\end{tabular}

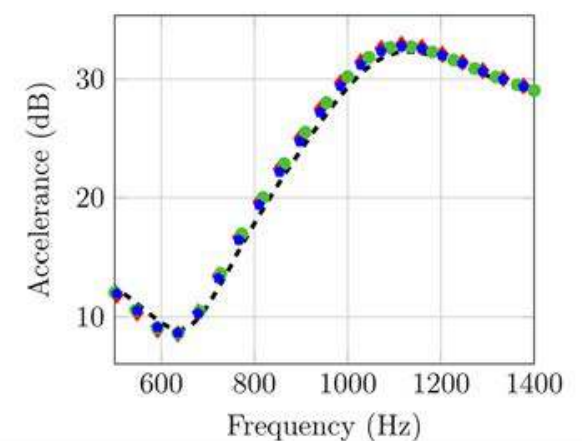

$\bullet 0.66 \times 0.17 \mathrm{~mm} \quad \bullet 0.75 \times 0.25 \mathrm{~mm} \cdot 1.32 \times 0.33 \mathrm{~mm} \quad \cdots 4 \mathrm{x} 1 \mathrm{~mm}$

Figure 9. Comparison of accelerance frequency evolution obtained from several mesh element sizes.

have at least 4 elements through the viscoelastic layer thickness while keeping a correct element shape factor, quadrilateral element sizing $0.75 \mathrm{~mm}$ and hexahedral element sizing $0.75 \times 0.25 \mathrm{~mm}$ are finally selected.

\section{Results and discussions}

\subsection{Comparison of numerical and experimental results}

In-plane dimensions and thicknesses of the manufactured plates presented in subsection 2.1 are set to the finite element model in order to reproduce the exact geometry of each plate sample, i.e by taking into account the slight variations of the thickness over the plate surface. Once the numerical models for static and dynamic analyses have been set-up, experimental results are used to validate/adjust both the carbon-epoxy and DYAD properties to be used in further numerical simulations.

\subsubsection{Fitting of carbon-epoxy laminate properties}

In a first step, three-points bending quasi-static tests are performed on three $5 \mathrm{~mm}$-thick carbon-epoxy plates. In order to adjust the material characteristics of the laminate, the numerical simulation of the 3-point bending test is run and confronted to experimental results, as illustrated in Figure 10. It is worth mentioning that the experimental curve plotted in this figure has been obtained by averaging the curves retrieved from the tests performed on three different specimens. Maximum and minimum measured values are highlighted with error bars. It appears that good fitting is obtained by setting the elastic modulus $\mathrm{E}_{11}$ to $90,000 \mathrm{MPa}$ for the simulations of carbon-epoxy plates. Additional simulations were realized varying the elastic modulii $E_{22}$ and $E_{33}$ but these parameters did not affect the results significantly. Such small sensitivity is due to the lay-up which includes the same number of 0 and $90^{\circ}$ plies. The stiffness of the skins in tension and compression is the same along 
direction 1 (fiber direction in $0^{\circ}$ ply) and direction 2 (fiber direction in $90^{\circ}$ ply).

In the same way, the loss factor of UD carbon-epoxy material to be used in finite element models is fitted by

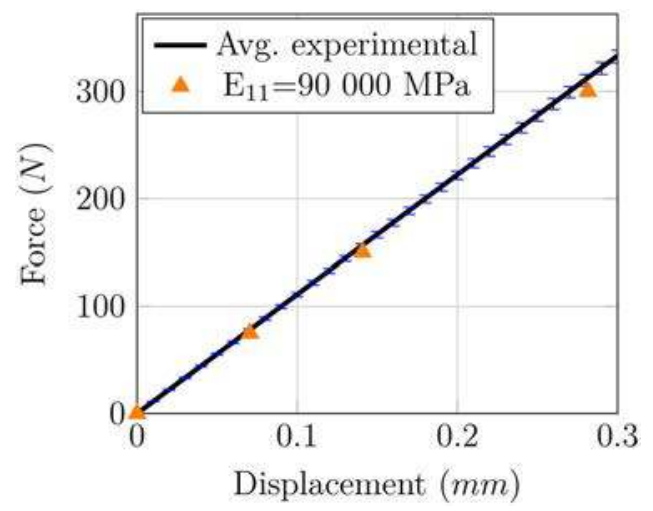

Figure 10. Three-points bending tests of carbon-epoxy plates: comparison of experimental and numerical results - Numerical results are shown with $\Delta$ while experimental ones are shown with continuous line.

Plate 1

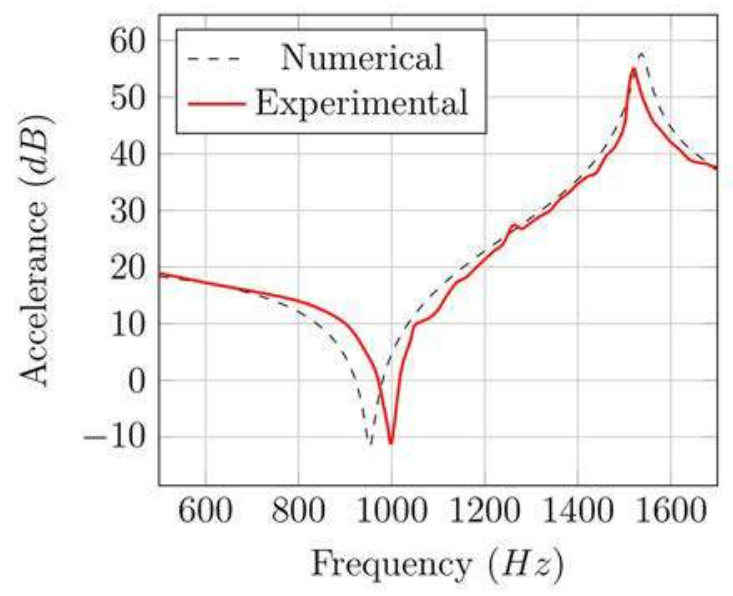

comparing the plate dynamic response extracted from the measurements with numerical simulations, for which the loss factor has been varied from 0.01 to 0.02 . Thus, numerical direct frequency response simulations are run considering each sample separately and resulting accelerance vs frequency curves are confronted in Figure 11 to experimental measures. In addition, peak values extracted from the experimental and numerical curves are compared in Table 6.

It is found that whatever the tested plate, a loss factor of 0.018 leads to the best correlation between numerical and experimental responses. The discrepancies related to resonant frequencies do not exceed $1.3 \%$ and the corresponding levels of accelerance differ by less than $10 \%$.

\subsubsection{Fully damped sandwich model validation}

In a second step, similar bending tests and numerical simulations are carried out for carbon-epoxy laminated plates including a viscoelastic layer. As for carbon-epoxy plates with S4R elements, the parameters required to define the

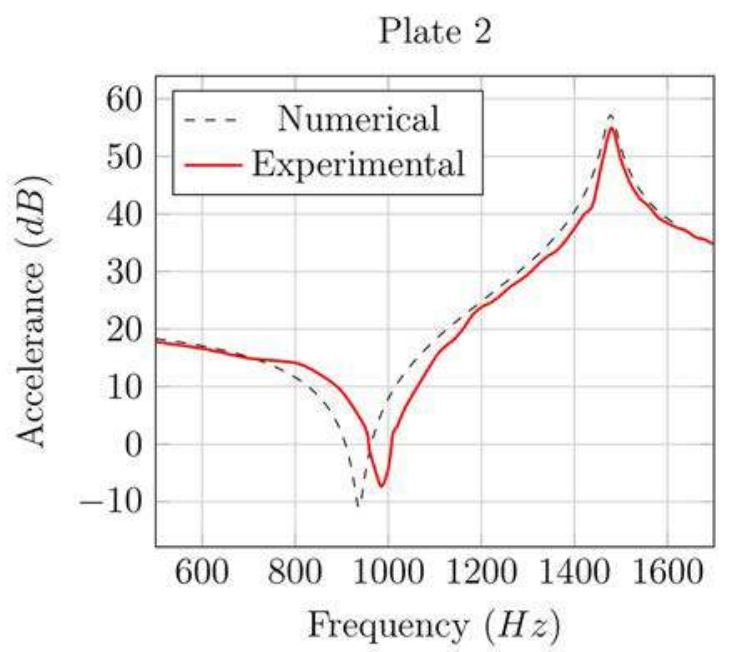

Plate 3

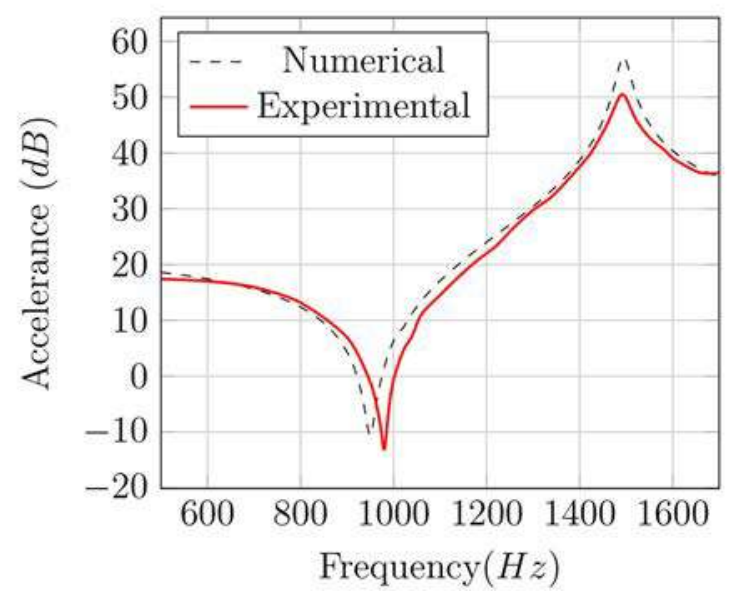

Figure 11. Frequency evolution of the accelerance at the plate center - Comparison of experimental and numerical results for the 3 manufactured carbonepoxy plates. 
visco-hyperelastic behavior law related to C3D8RH solid elements are set based on Table 3 and Figure 5 .

As the stiffness of the resulting sandwich is concerned, Figure 12(a) clearly shows that using carbon-epoxy elastic modulus $E_{11}=90,000 \mathrm{MPa}$ combined with DYAD601 static characteristics provided by the manufacturer allows to obtain a good correlation.

The dynamic behavior of the sandwich plates is also addressed with the objective to confirm the use of DYAD601 frequency dependant viscoelastic properties extracted from DMA tests. At each frequency step, when setting the stiffness matrix $K$, the complex shear modulus $G^{*}$ is recalculated using the following expressions:

$$
\begin{gathered}
\omega R\left(G^{*}\right)=\frac{G^{\prime \prime}}{G} \\
\omega I\left(G^{*}\right)=1-\left(\frac{G^{\prime}}{G}\right)
\end{gathered}
$$

Where $G^{\prime \prime}$ is the loss shear modulus, $G^{\prime}$ is the storage shear modulus and $\mathrm{G}$ is the static shear modulus

Numerical direct frequency response analysis is thus performed on the second set of plates and resulting accelerance vs frequency curve is compared in Figure 12(b) to the experimental one. As for carbon-epoxy plates, remarkable values extracted from these curves are presented in Table 7 , where it can be noted that the discrepancies between numerical and experimental values do not exceed $0.8 \%$. The higher

Table 6. Summary of the results obtained from experimental test and finite element simulation on Carbon epoxy samples.

\begin{tabular}{lcccccc}
\hline Plate & \multicolumn{3}{c}{ Peak amplitude $[d B]$} & \multicolumn{3}{c}{ Natural frequency $[\mathrm{Hz}]$} \\
\hline & Num. & Exp. & Discrepancy & Num. & Exp. & Discrepancy \\
P1 & 57 & 55 & $3.5 \%$ & 1539 & 1520 & $1.3 \%$ \\
P2 & 57 & 55 & $3.5 \%$ & 1480 & 1480 & $0 \%$ \\
P3 & 57 & 51 & $10 \%$ & 1495 & 1490 & $0.4 \%$ \\
\hline
\end{tabular}

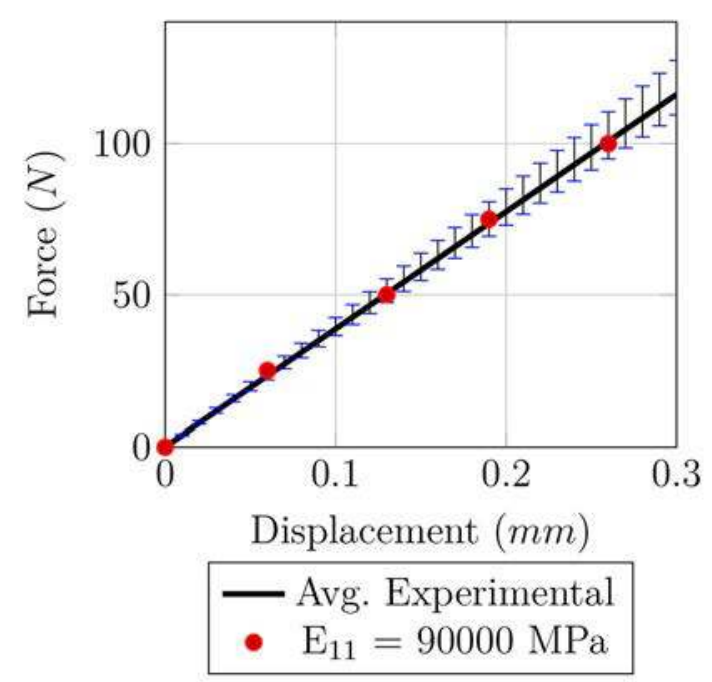

(a) Three-point bending tests on carbon-epoxy plates including a viscoelastic layer - Numerical results are shown with $\circ$ and the average of experimental ones is represented by the continuous line. difference observed at the antiresonance is probably due to the contribution of the swinging rigid body mode at $0.9 \mathrm{~Hz}$ (remember that the plate is suspended to the frame with nylon threads), which is not captured by the simulation where free-free boundary conditions have been assumed.

Despite the discrepancy observed at the antiresonance, it is reasonable to say that the numerical model allows to reproduce in a satisfactory manner the experimental measurements.

\subsubsection{Confrontation of the "bridged" sandwich model to experimental results}

Three-points bending tests are also performed on three plates of the third set, for which the carbon-epoxy laminate includes 9 bridges of resin between upper and lower skins (see Figure 1). On the numerical side, the bending stiffness appears to be far higher than the one extracted from the measurements. The question then arises as to whether some of the holes created in the viscoelastic film are not completely filled by the resin during the co-curing phase, leading to a lower surface of bridges compared to the expected one. Therefore, several cutouts are performed on the manufactured "bridged" sandwiches followed by a progressive sanding to analyze the section passing through the greatest diameter of the bridges.

Figure 13 shows two different bridge sections and highlights two main defects. On the left side, it is observed that the maximal diameter of the bridges is close to $8.5 \mathrm{~mm}$, while $10 \mathrm{~mm}$ circular holes have been initially created. This defect, observed in almost all the bridges, is probably due to the fact that the DYAD601 layer is compressed during the co-curing process, which seems to reduce the diameter of holes when the resin flows inside. On the right side, a lack of epoxy is also observed: it seems that the volume of resin

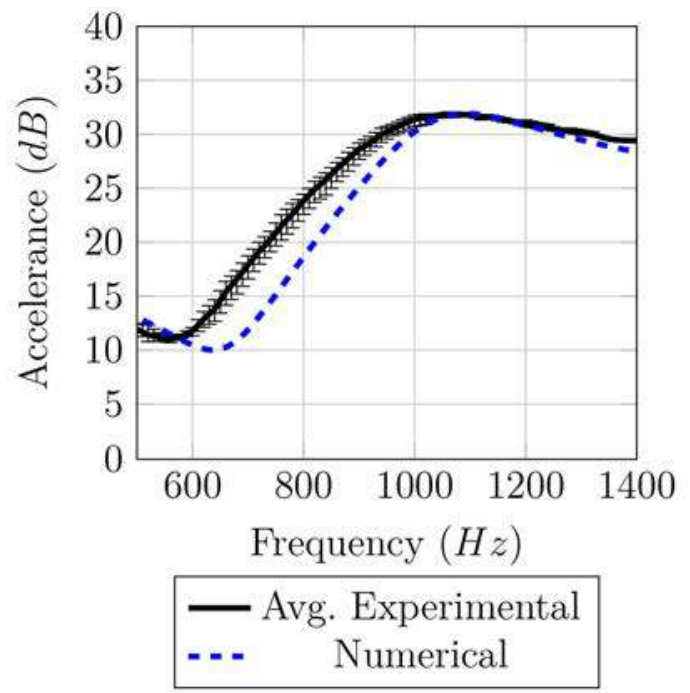

(b) Frequency evolution of the accelerance at the plate center - Comparison of experimental and numerical results for carbon-epoxy plates including a viscoelastic layer

Figure 12. Numerical vs experimental results for carbon-epoxy plates including a viscoelastic layer. 
included in the prepreg is not sufficient to entirely fill the holes made in the viscoelastic layer.

In order to investigate the number and location of holes which may have been actually filled, different bridge configurations incorporating 9, 5, 4 and 3 bridges (see Figure 14) are simulated considering the fitted material characteristics. In Figure 15(a) which compares the resulting force vs displacement curves, the experimental data corresponds to the average of the bending test results performed on three specimens and the error bars correspond to minimum and maximum measured values. This figure clearly shows that the bridges located near the plate corners bring more stiffness than the ones located near the center. Moreover, comparing the slope of the different curves, one may notice that additional stiffness is much more important when the location of the bridges is changed (e.g., going from the 4-bridges configuration to the 5-bridges one), than when the bridge number is changed (e.g., going from 5 to 9 bridges). In other words, the location of the bridges seems to influence much more the stiffness that the number of bridges. Figure 15(a) also shows that the curve related to the 4-bridges configuration is the one that correlates better with the experimental curve. That is why this configuration will be further considered to simulate the frequency response of the third set of plates.

A direct frequency response analysis is finally performed on a "bridged" sandwich, considering only 4 bridges to reproduce the bending stiffness of the manufactured plates. Numerical and experimental accelerances are compared in Figure 15(b) and Table 8. However, we are aware that the agreement obtained between the 4-bridges numerical model and experiments does not mean that the tested plates have actually four bridges completely filled with resin and the others without resin. Further study should be carried out to identify, thanks to an inverse approach, the number of bridges with resin and their diameter. But we lack of experimental results such as mode shapes to perform such

Table 7. Summary of the results obtained from experimental tests and finite element simulation of carbon-epoxy plates including a viscoelastic layer.

\begin{tabular}{lccccc}
\hline & Peak amplitude $[d B]$ & \multicolumn{3}{c}{ Natural frequency $[\mathrm{Hz}]$} \\
\hline Num. & Exp. & Discrepancy & Num. & Exp. & Discrepancy \\
31.9 & 31.8 & $0.4 \%$ & 1089 & 1092 & $0.8 \%$ \\
\hline
\end{tabular}

kind of study. In addition, it is not desirable to use a process which leads to manufacturing uncertainties. This is why, in the following, it will be assumed that the manufacturing process will be improved in order to obtain plates with bridges of the desired diameter that are completely filled with resin.

\subsection{Influence of the viscoelastic layer}

In this section, static and dynamic responses extracted from the measurements made on the three different sets of plates are compared. In Figure 16(a), one observe that including a non perforated constrained viscoelastic layer decreases the structure bending stiffness by $65 \%$ compared to an undamped carbon-epoxy plate (see Table 9). However, creating bridges between the upper and lower skins allows to reduce the stiffness loss to $54 \%$.

When comparing in Figure 16(b) the experimental forced responses of the different sets of plates, it is observed that resonance frequencies, accelerance peak levels and damping values are very sensitive to both the presence of the viscoelastic layer and inclusion of bridges. More precisely, Table 10 shows that inserting into the carbon-epoxy laminate a viscoelastic film allows to decrease by around $23 \mathrm{~dB}$ the accelerance peak level compared to the undamped plate. On the other side, creating bridges between lower and upper skins allows to decrease the accelerance peak level by around $20 \mathrm{~dB}$. Table 10 also shows that the first natural frequency of

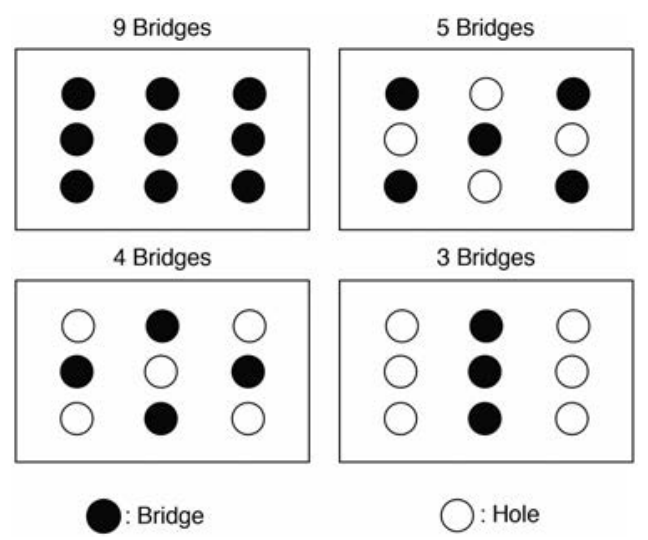

Figure 14. Holes and bridges location.

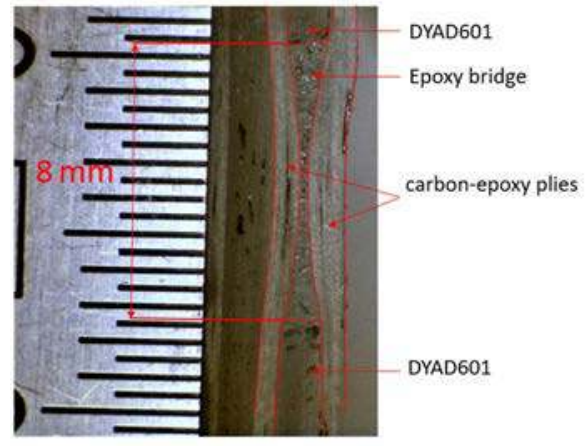

(a) Defect of bridge shape and size

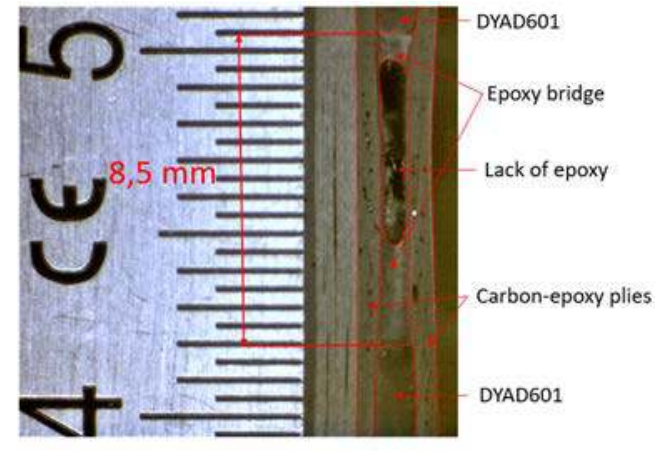

(b) Defect of bridge filling

Figure 13. Micro-analysis of resin bridges. 


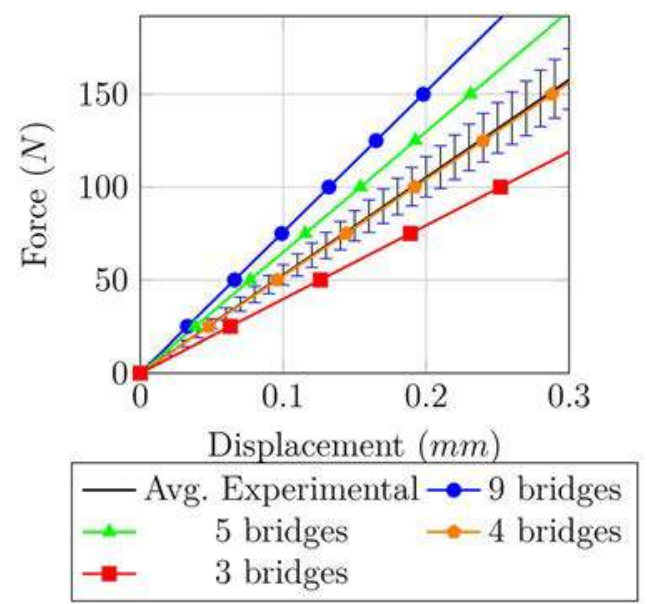

(a) Three-point bending static response

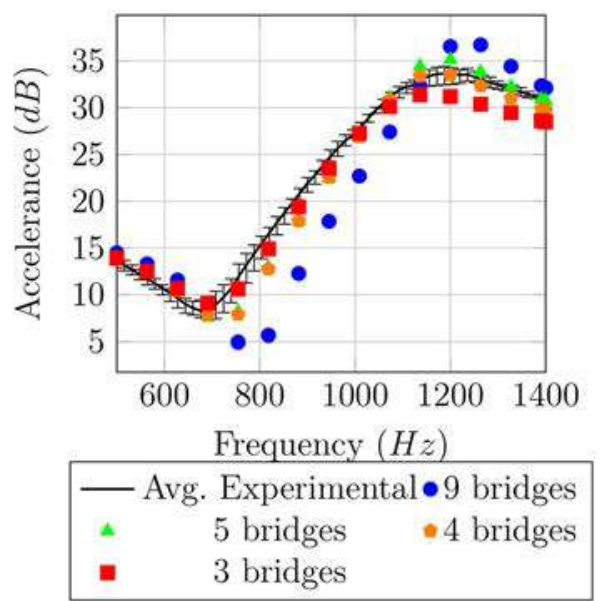

(b) Dynamic response

Figure 15. Numerical vs experimental results for carbon-epoxy plates including one viscoelastic layer and bridges - Numerical results are shown with ${ }^{\circ}, \triangle, \square, \square$ and experimental ones are shown with continuous lines.

Table 8. "Bridged" sandwich plate: comparison of first natural frequency and peak amplitude.

\begin{tabular}{|c|c|c|c|c|c|}
\hline \multicolumn{3}{|c|}{ Peak amplitude $[d B]$} & \multicolumn{3}{|c|}{ Natural frequency $[\mathrm{Hz}]$} \\
\hline Num. & Exp. & Discrepancy & Num. & Exp. & Discrepancy \\
\hline 34.2 & 33.7 & $1.5 \%$ & 1150 & 1182 & $2.4 \%$ \\
\hline
\end{tabular}

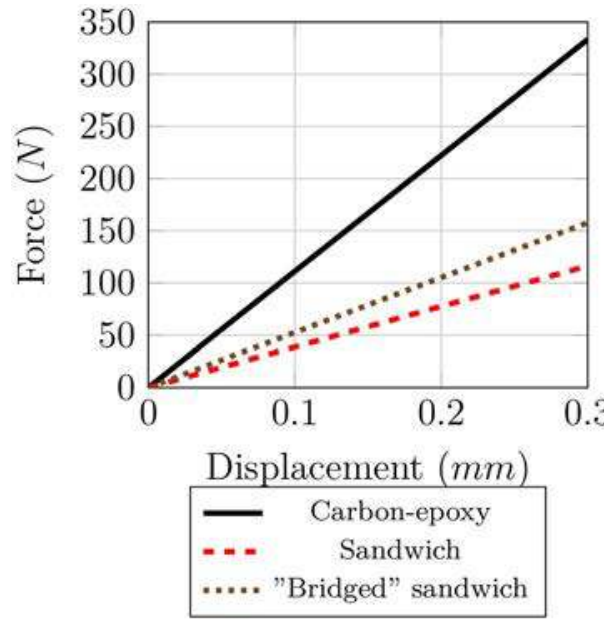

(a) Three-point bending test

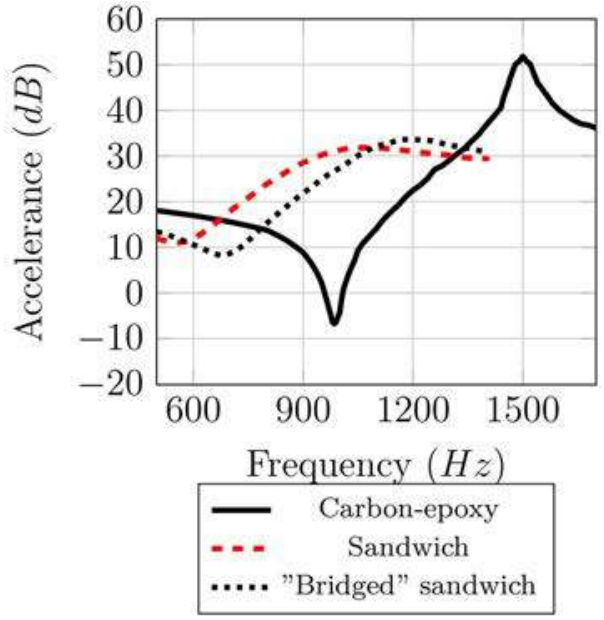

(b) Forced response test

Figure 16. Comparison of test results for the three types of plates.

Table 9. Comparison of resulting bending stiffness.

\begin{tabular}{|c|c|c|c|}
\hline & Carbon epoxy with DYAD & Carbon epoxy with perforated DYAD & Carbon-epoxy plates \\
\hline K: Stiffness $[N / m m]$ & 387 & 508 & 1111 \\
\hline Stiffness loss & $65 \%$ & $54 \%$ & I \\
\hline
\end{tabular}

Table 10. Summary of forced response results.

\begin{tabular}{lccc}
\hline & $\begin{array}{c}\text { Peak } \\
\text { amplitude } \\
{[\mathrm{dB}]}\end{array}$ & $\begin{array}{c}\text { Natural } \\
\text { frequency } \\
{[\mathrm{Hz}]}\end{array}$ & $\begin{array}{c}\mathrm{dB}_{C E} \\
{[\mathrm{~dB}]}\end{array}$ \\
\hline Plates set & 53 & 1500 & $/$ \\
Darbon-epoxy plate & 31.8 & 1092 & 21.2 \\
"Bridged" damped plate & 33.7 & 1182 & 19.3 \\
\hline
\end{tabular}

the plate is shifted from around $1500 \mathrm{~Hz}$ to $1092 \mathrm{~Hz}(28 \%$ lower) for the full viscoelastic sandwich and to $1182 \mathrm{~Hz}$ (22\% lower) for the "bridged" one.

\section{Sensitive analysis of bridges on stiffness and damping}

\subsection{Influence of bridge location and size: analysis of a "bridged" sandwich beam}

A sensitivity analysis is performed on a "Equasi-2D" simply supported beam to investigate to which extent the bridge location and size affect its static and dynamic behavior. The beam has 2 bridges, symmetrically located. Four different locations defined in Table 11 are considered as well as four 
different bridge volume fractions, i.e the percentage of beam volume occupied by the bridge, varying from $0.75 \%$ $\left(0.5 \mathrm{~mm}^{3}\right)$ to $6 \%\left(4.2 \mathrm{~mm}^{3}\right)$ with two intermediate values.

The beam dimensions and sandwich lay-up are as follows:

- Beam length: $140 \mathrm{~mm}$

- Beam thickness: $6 \mathrm{~mm}$

- Beam width: $1 \mathrm{~mm}$

- Lay-up: $[0,90,90,0, \text { DYAD601 }]_{s}$

- Carbon-epoxy skin thickness: $2.5 \mathrm{~mm}$

- DYAD601 layer thickness: $1 \mathrm{~mm}$

The beam is assumed to be supported at $5 \mathrm{~mm}$ from its extremities and loaded at mid-span.

The stiffness ratio $K / K C E$ is calculated from a $2 \mathrm{D} \mathrm{FE}$ model under plane stress assumption for the 16 configurations (combining 4 locations with 4 volume fractions). Resulting values are compared in Figure 17(a) and Table 12. $K$ is the stiffness of the "bridged" damped beam and $K C E$ the stiffness of the undamped carbon-epoxy beam.

Similarly, the attenuation ratios A/Avisco are compared in Figure 17(b) and Table 13. Here, Avisco is the attenuation of the fully damped beam (without bridge). $A$ and Avisco are calculated as:

$$
\begin{aligned}
& \left.A(\omega)=20 \log _{10}\left(\frac{a_{\text {carbon }}(\omega)}{F(\omega)}\right)-20 \log _{10} \frac{a_{\text {conf }}(\omega)}{F(\omega)}\right) \\
& A_{\text {visco }}(\omega)=20 \log _{10}\left(\frac{a_{\text {carbon }}(\omega)}{F(\omega)}\right)-20 \log _{10}\left(\frac{a_{\text {visco }}(\omega)}{F(\omega)}\right)
\end{aligned}
$$

Where $a_{\text {carbon }}(\omega), a_{\text {conf }}(\omega), a_{v i s c o}(\omega)$ are the acceleration amplitudes post-processed at the center of the carbon-epoxy, "bridged" damped and fully damped carbon-epoxy beams

Table 11. Bridge locations.

\begin{tabular}{lcccc}
\hline Position $\mathrm{n}^{\circ}$ & 1 & 2 & 3 & 4 \\
\hline Distance from beam extremity $[\mathrm{mm}]$ & 20.7 & 36.4 & 52.2 & 67.9 \\
\hline
\end{tabular}

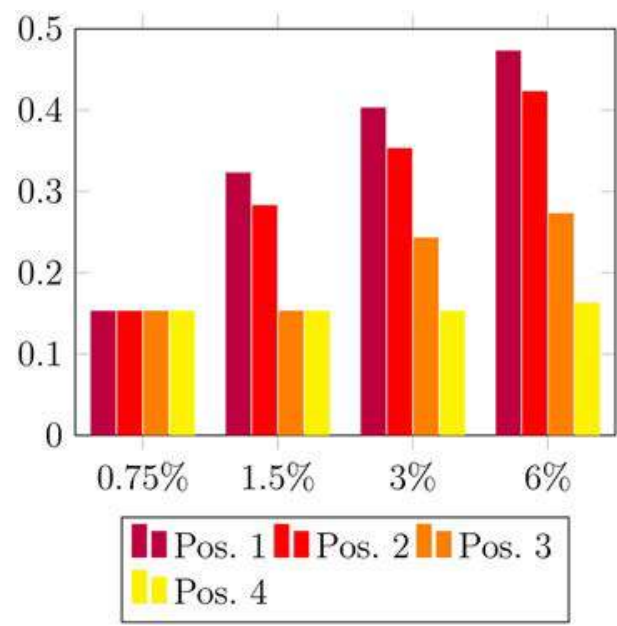

(a) Evolution of $\mathrm{K} / \mathrm{KCE}$ respectively and $F(\omega)$ is the amplitude of the applied force. The ratio $K / K C E$ varies from 0.15 (fully damped beam) to 1 (undamped beam). The ratio A/Avisco varies from 0 (undamped beam) to 1 (fully damped beam). Reducing the level of a "bridged" beam dynamic response comes to maximize this ratio.

The following observations may be done:

- Whatever the location of the bridge, a beam with a small bridge volume fraction $(0.75 \%)$ behaves like a fully damped beam (see the gray first column in Tables 12 and 13).

- Whatever the volume fraction, a bridge located close to the beam center (position 4 - yellow bars) leads also to a behavior similar to the one of a fully damped beam (see the gray last row in Tables 12 and 13).

- The influence of the bridge on both the bending stiffness and damping is as expected more important when the volume fraction increases.

- When the bridge gets closer to the support, the loss of stiffness is smaller (see Figure 17(a)) and the loss of damping larger (see Figure 17(b)).

The last point may be easily justified by analyzing in Figure 18 the spatial evolution of the elastomer transverse shear deformation, post-processed for the different bridge configurations. It appears that $\gamma_{x z}$ increases when the bridge comes close to the support. However, the presence of the bridge tends to limit this evolution, and is more pronounced as the bridge is closer to the support.

This first sensitivity analysis carried out on a "quasi-2D" beam clearly shows that the main challenge consists in finding the best compromise between damping and stiffness. In other words, optimizing a damped composite plate that includes resin bridges comes to find the best spatial distribution and size of the bridges to maximize the damping while keeping a reasonable bending stiffness.

Let us now consider a $500 \times 250 \mathrm{~mm}$ carbon-epoxy plate including a DYAD601 layer. In the parametric study presented below, from 0 to 9 holes with different diameters are

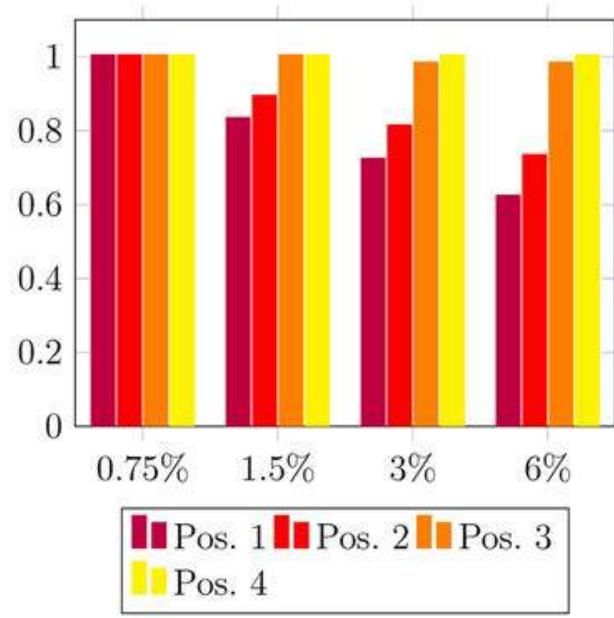

(b) Evolution of A/Avisco

Figure 17. Simply supported beam: sensitivity to bridge location and bridge volume fraction. 
Table 12. Values obtained for K/KCE.

\begin{tabular}{lllll}
\hline & \multicolumn{5}{c}{ Volume fraction (\%) } \\
\hline Bridge position & 0.75 & 1.5 & 3 & 6 \\
1 & 0.15 & 0.32 & 0.40 & 0.47 \\
2 & 0.15 & 0.28 & 0.35 & 0.42 \\
3 & 0.15 & 0.15 & 0.24 & 0.27 \\
4 & 0.15 & 0.15 & 0.15 & 0.16 \\
\hline
\end{tabular}

Table 13. Values obtained for A/Avisco.

\begin{tabular}{lcccc}
\hline & \multicolumn{5}{c}{ Volume fraction (\%) } \\
\hline Bridge position & 0.75 & 1.5 & 3 & 6 \\
1 & 1 & 0.84 & 0.72 & 0.63 \\
2 & 1 & 0.90 & 0.81 & 0.74 \\
3 & 1 & 1 & 0.99 & 0.98 \\
4 & 1 & 1 & 1 & 1 \\
\hline
\end{tabular}

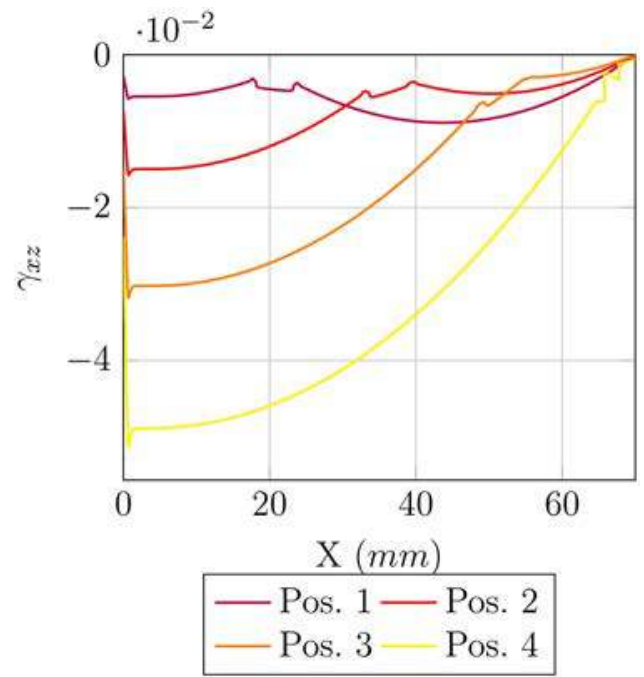

Figure 18. Spatial evolution of DYAD601's transverse shear strain for different bridge locations.

supposed to be entirely filled by the resin during the co-curing process. The numerical model that has been validated in previous section is used to simulate a certain number of configurations with the objective to build a design of experiments.

\subsection{Influence of bridge location and size: analysis of a "bridged" sandwich plate}

The dimensions of the "bridged" sandwich plates considered as well as the position of the holes are depicted in Figure 19. The plate particulars are the following ones:

- Dimensions: $500 \times 250 \times 6 \mathrm{~mm}$

- DYAD601 layer thickness: $1 \mathrm{~mm}$

- Skins carbon-epoxy thickness: $2.5 \mathrm{~mm}$

- Lay-up: $[0,90,90,0, D Y A D 601]_{S}$

The dynamic response of the free-free plate is investigated in a frequency range that includes its first four natural frequencies. A sinusoidal force is applied perpendicularly to the plate and its location is chosen so as to excite properly the mode shapes depicted in Figure 20. The first four

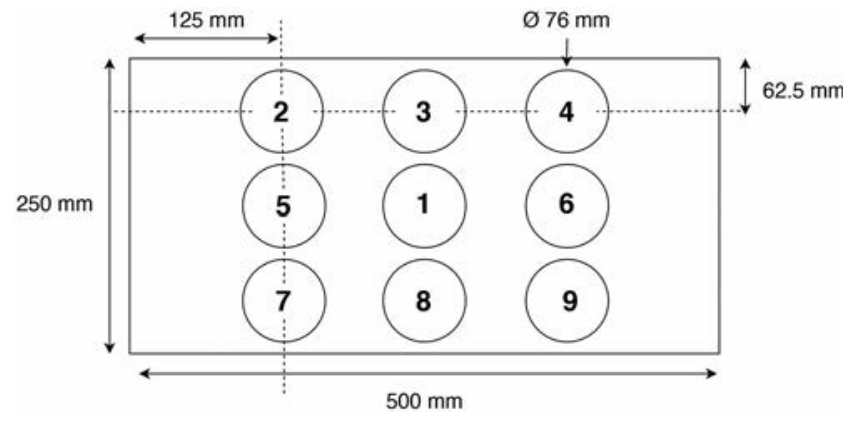

Figure 19. Plate dimensions and bridges location.

natural frequencies calculated for both the undamped and fully damped plates are listed in Table 14.

Some authors used the modal damping as the parameter to maximize in order to define a cost function [11, 28, 29]. We inspired from this articles in order to build a cost function able to capture the damping related to the first 4 natural modes.

Maximizing the damping while keeping a reasonable bending stiffness may be done by defining the following optimization function:

- A cost function $F c$ is defined so as to maximize the modal damping related to the first four modes:

$$
F c=\sum_{i=1}^{4} \frac{\eta_{i}-\eta_{C E i}}{\eta_{v i s c o i}-\eta_{C E i}}
$$

Where $\eta_{i}, \eta_{C E i}, \eta_{v i s c o i}$ are the modal damping values of the $i^{\text {th }}$ mode of "bridged," undamped and fully damped plates respectively. The $-3 d B$ bandwidth method is considered to extract the damping value at each natural frequency.

- The optimization is performed under the constraint that the stiffness of the "bridged" sandwich plate must be higher of equal to half of the undamped carbonepoxy plate.

\subsection{Set-up of a design of experiments}

The approach to find the optimal configuration is based on the construction of a design of experiments (DOE) [30] which is an efficient approach for computational savings. The parameters of a DOE are called "factors" and the results are called "responses." Based on a limited number of finite element simulations (128 in our case), the DOE aims to determine the contribution (the weight) of each factor, individually, on the response. A second order polynomial function is thus built, its predictive nature is checked and finally the function is used to approximate the response considering all the possible configurations.

As the plate includes between 0 and 9 bridges with 4 different diameters and different bridge locations, 2048 different configurations should be analyzed to identify the optimum one. Based on numerical simulations, such analysis would require $2700 \mathrm{CPU}$-hours on a 16 core $/ 3.2 \mathrm{GHz}$ computer together with around 1000 hours to post-process the 


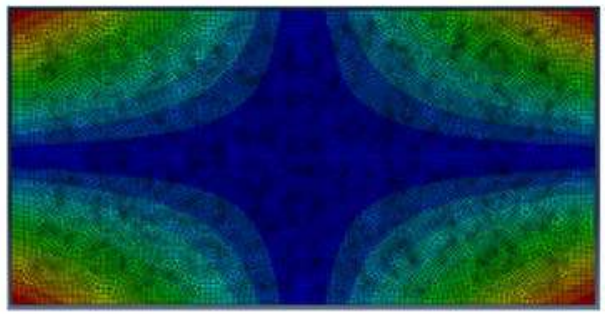

(a) $1^{\text {st }}$ Mode - Torsion

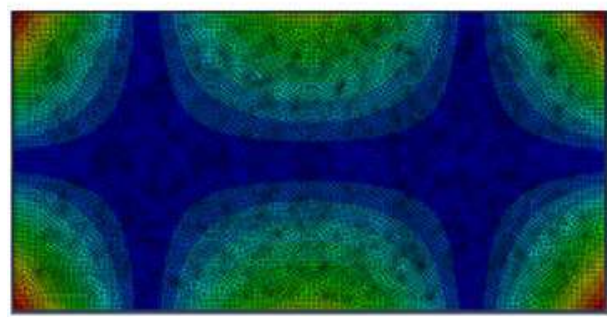

(c) $3^{\text {rd }}$ Mode - Torsion

Figure 20. First four natural mode shapes.

Table 14. First four natural frequencies of the plates.

\begin{tabular}{lcccc}
\hline & Mode 1 [Hz] & Mode 2 [Hz] & Mode 3 [Hz] & Mode 4 [Hz] \\
\hline Undamped plate & 91 & 150 & 238 & 413 \\
Fully damped plate & 84 & 144 & 219 & 349 \\
\hline
\end{tabular}

results. The use of a DOE allows to significantly decrease the optimization process.

The 128 configurations simulated numerically are chosen to respect the orthogonality of the DOE, which allows to vary the different factors simultaneously while defining independently the influence of each factor on the response. A second order polynomial form based on linear and quadratic factors as well as interactions between them is built to estimate the response. As the bridge diameter is the only parameter that can take more than 2 different values, it is also the only one related to a quadratic term. The polynomial form may thus be written as:

$$
y=\beta_{0}+\sum_{i=1}^{k} \beta_{i} x_{i}+\sum_{i<j}^{k} \beta_{i j} x_{i} x_{j}+\beta_{11} x_{1}^{2}
$$

- $y$ is the response,

- $\beta_{0}$ is a constant,

- $\beta_{i}$ are the coefficients of the linear factors,

- $\beta_{i i}$ are the coefficients of the quadratic factors,

- $\beta_{i j}$ are the coefficient of the interactions,

- $x_{i}(\mathrm{~A} \rightarrow \mathrm{K}), x_{1}^{2}(\mathrm{AA})$ and $x_{i j}(\mathrm{AB} \rightarrow \mathrm{JK})$ are the linear, quadratic and interaction factors (see Tab.15 below for the factors names).

The factors considered in the optimization of the "bridged" sandwich plate together with their possible values are presented in Table 15 .

The plate static deflection, modal damping values, and cost function are investigated as DOE responses. This means that six polynomial functions will be built, one for the static

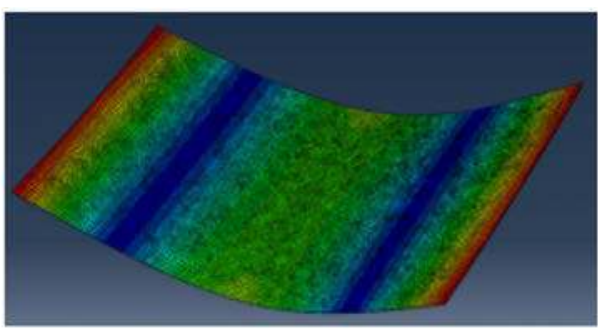

(b) $2^{\text {nd }}$ Mode - Bending

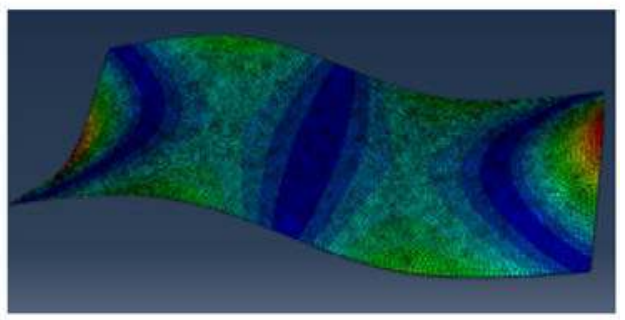

(d) $4^{\text {th }}$ Mode - Bending
Table 15. DOE factors.

\begin{tabular}{|c|c|c|}
\hline Factor & Parameter & Values \\
\hline $\bar{A}$ & Bridge diameter & $30 \mathrm{~mm}, 51 \mathrm{~mm}, 66 \mathrm{~mm}, 76 \mathrm{~mm}$ \\
\hline B & bridge $n^{1}$ & Full (1) or Empty (0) \\
\hline C & bridge $\mathrm{n}^{\circ} 2$ & Full (1) or Empty (0) \\
\hline D & bridge $n^{\circ} 3$ & Full (1) or Empty (0) \\
\hline $\mathrm{E}$ & bridge $n$ & Full (1) or Empty (0) \\
\hline $\mathrm{F}$ & bridge $\mathrm{n} 5$ & Full (1) or Empty (0) \\
\hline G & bridge $n^{0} 6$ & Full (1) or Empty (0) \\
\hline $\mathrm{H}$ & bridge $n 7$ & Full (1) or Empty (0) \\
\hline $\mathrm{J}$ & bridge $\mathrm{n}^{\circ} 8$ & Full (1) or Empty (0) \\
\hline $\mathrm{K}$ & bridge $\mathrm{n} 9$ & Full (1) or Empty (0) \\
\hline
\end{tabular}

deflection, one for the cost function and four for modal damping values related to the first four natural modes. The optimization process may thus be split into the following steps:

- Plate deflection, modal damping values as well as cost function are post-processed from the finite element simulations carried out on the 128 chosen configurations.

- A least-square linear regression is then realized on each response and resulting second order polynomial functions are set.

- A chart showing the polynomial vs residual values is plotted to check both the maximum gap between numerical and polynomial results and the randomness of the error distribution.

- A normalized effect Pareto chart is plotted to analyze the contribution of each factor and discard those having a non-significant impact on the response.

- Once the non significant factors have been eliminated, the predictive capacity of the new polynomial form is calculated for each response in order to check its ability to predict the remaining $2048-128=1920$ configurations.

- The configuration which maximizes the cost function while complying with the stiffness constraint is identified. 


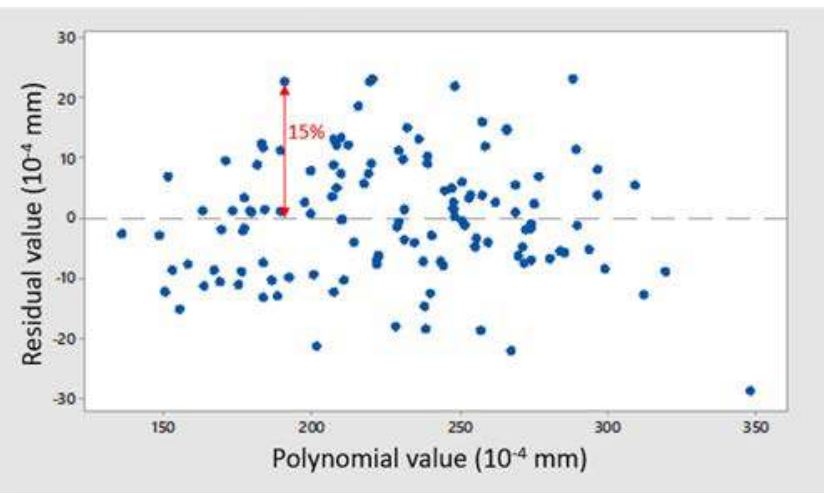

Figure 21. Residual value vs polynomial values.

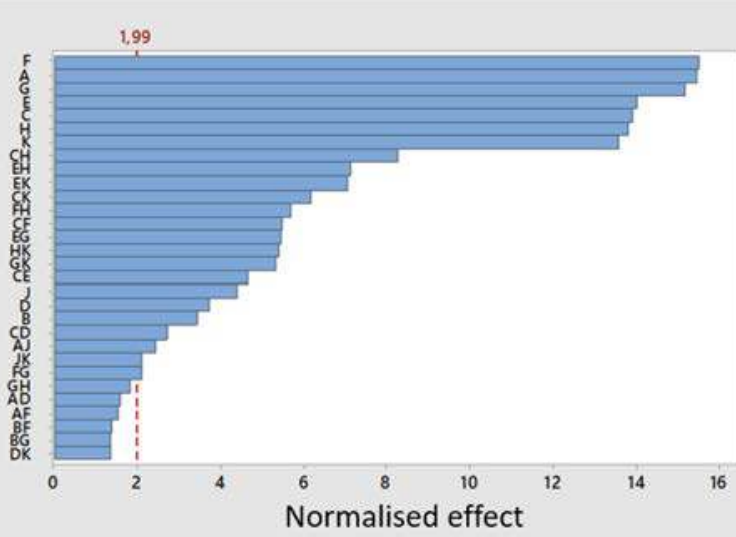

Figure 22. Pareto normalized effect.

\subsection{Influence of the DOE factors on the plate stiffness}

First of all, the deflection of a simply supported plate loaded by a transverse force is investigated. The supports are located at $5 \mathrm{~mm}$ from the small edges of the plate and a unit load is applied at its center. Starting from the deflections retrieved from the 128 numerical simulations, a DOE is setup using Minitab software.

Figure 21 shows the polynomial vs residual value chart. Residual value represents the discrepancy between the deflection predicted by the polynomial function and the one retrieved from the numerical simulation. The gap, determined as the ratio of the residual value to the associated polynomial one, does not exceed $15 \%$ whatever the point depicted on this graph. This result also means that the predictive polynomial form can be used in place of the numerical model if the design tolerance is higher than $15 \%$.

The chart displayed in Figure 21 may also be used to check the randomness of the residual values. Here, it appears clearly that the distribution is pseudo-randomised around the 0 -axis and may be considered as acceptable.

The Pareto normalized effect chart displayed in Figure 22 aims to measure the influence of both the factors and their interactions over the response. It is obtained in the following way. The probability of each factor to be retained without having a real effect on the response is calculated. Then, to distinguish significant from non significant factors, the

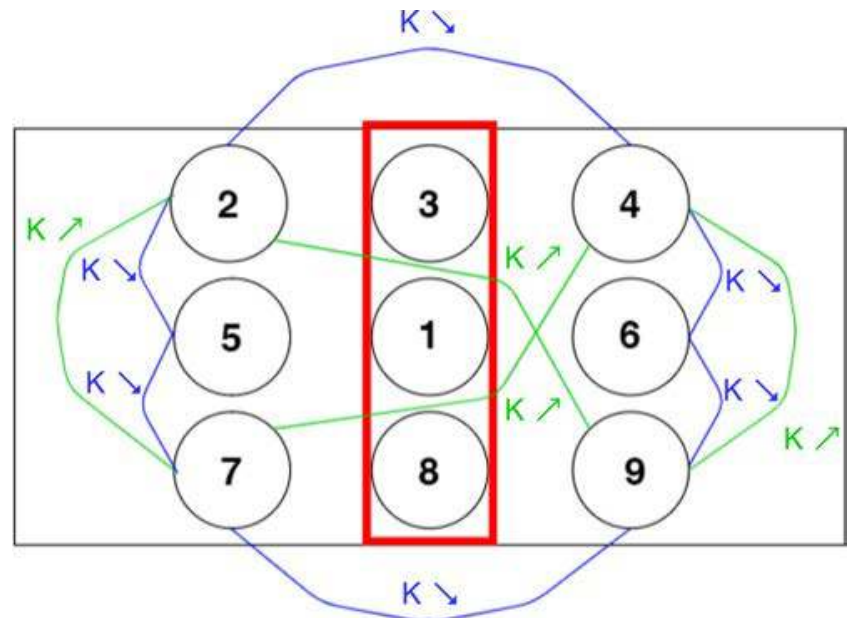

Figure 23. Location of non significant bridges and interactions between neighboring and distant bridges.

commonly used threshold value of $5 \%$ is considered. This means that when the aforementioned probability is less than $5 \%$, the factor is considered to be non-significant. Based on the DOE used in this study, the threshold value of $5 \%$ is obtained for a normalized effect of 2 (highlighted by the red line in Figure 22). The significant factors are thus the ones having a normalized effect higher than 2 .

The Pareto chart shows that the quadratic factor does not contribute significantly to the plate deflection. On contrary, linear factors appear to have the highest probability to be significant, even if the influence of factors B, D and J, which correspond to bridges 1,3 and 8 (surrounded by the red line in Figure 23) is less. From a mechanical point of view, this may be explained by the fact that the transverse shear strain at mid-span is small, as already demonstrated for the simply supported "quasi-2D" beam. The bridges located at mid-span have a small effect on the elastomer transverse shear strain and, as a consequence, do not affect significantly the bending response of the plate.

A first estimation of the capacity of the polynomial to predict the plate deflection is realized taking in account all the factors. Then, two additional estimations are performed, the first one keeping only the significant factors and the second one keeping only the linear factors. The $R^{2}$ is the criterion commonly used to measure the capacity of the polynomial function to predict the response. However, this criterion is clearly questionable because adding new terms to the polynomial always improves the $R^{2}$ value, even though such improvement may be coincidental. To overcome this problem, two other criteria may be considered. The first one is the so-called $R^{2}$ adjusted criterion, which takes into account the number of retained factors. As removing less probable factors usually improves the $R^{2}$ adjusted, a second criterion called $R^{2}$ expected is calculated by eliminating each measurement from the data, one by one, then by recalculating the regression coefficients without the discarded measurement. In fact, the $R^{2}$ expected value measures the capacity of the polynomial form to predict the response considering new observations. Table 16 gives the value of the $R^{2}$ expected for the three aforementioned estimations. 
Table 16 clearly shows that the model prediction capacity is higher when only the significant factors including the interaction terms are considered. As the number of factors is less, the risk of error due to non significant factors is decreased. Finally, the best polynomial function obtained for the prediction of the "bridged" damped plate deflection is the following one:

$$
\begin{aligned}
& w_{\max }=369.51-0.7222 * A-6.59 * B-23.94 * C \\
& -12.88 * D-19.56 * E-51.97 * F \\
& \quad-50.38 * G-18.75 * H+5.75 * J-21.75 * K \\
& -0.270 * A J+10.38 * C D+17.81 * C E \\
& +21.06 * C F-31.69 * C H-23.62 * C K+20.81 * E G \\
& -27.31 * E H-27.00 * E K \\
& +21.81 * F H+20.38 * G K+20.75 * H K
\end{aligned}
$$

A thorough analysis of Eq. (13) allows to better understand the interactions between the different bridges. Each linear factor (each bridge) is associated with a negative coefficient, which means, as expected, that every bridge contributes to decrease the deflection, i.e. to increase the plate stiffness.

It is also observed that interactions between 2 neighboring bridges are associated with positive coefficients, meaning that the deflection is less decreased compared to what would be obtained by adding the influence of the bridges taken one by one. This may be explained physically as follows. A bridge modifies the shear behavior of the mid-layer within a certain area. When two bridges are in close proximity, their respective area of influence overlap and, as a consequence, their stiffening effect are less than additive.On contrary, interaction coefficients related to distant bridges are negative, showing the favorable effect of distant bridges over the plate stiffness. Physically, the stiffening effect of distant bridges is more efficient because the overlap of stiffened

Table 16. Capacity of the polynomial function to predict the static deflection.

\begin{tabular}{lccc}
\hline & All factors & Significant factors & Linear factors \\
\hline$R^{2}$ expected & $88 \%$ & $92 \%$ & $77 \%$ \\
\hline
\end{tabular}

Table 17. Capacity of the polynomial forms to predict the modal damping values.

\begin{tabular}{lllll}
\hline & Mode 1 & Mode 2 & Mode 3 & Mode 4 \\
\hline$R^{2}$ expected & $96 \%$ & $96 \%$ & $97 \%$ & $93 \%$ \\
\hline
\end{tabular}

areas is smaller or even null. Figure 23 illustrates the interactions between neighboring and distant bridges.

Finally, it is worth noting that among the 128 numerical simulations used to set the DOE, only 43 led to a stiffness higher than half the stiffness of the carbon-epoxy plate.

\subsection{Influence of the DOE factors on the plate damping}

In a second part, modal damping values calculated for the first 4 modes are considered and new DOE are built. As for the plate deflection, Pareto and polynomial vs residual value charts are analyzed and a polynomial function is derived to predict the modal damping values. For each mode, the capacity of prediction characterized by the $R^{2}$ expected value is given in Table 17.

The coefficients of the resulting polynomial functions are listed in Table 18. It may be observed that interactions between neighboring and distant bridges are not significant. Only the interactions involving the bridge diameter and the bridges themselves have an influence on the plate damping. As expected, linear and interaction coefficients are all negative, which means that every bridge contributes to reduce the modal damping.

In Figure 24, the bridges having any or few influence on the modal damping values are highlighted. To explain this physically, let us choose a configuration involving 2 neighboring bridges, one located in the plate diagonal and one located at mid-width. Figure 25 presents the transverse shear strain distribution post-processed in the viscoelastic layer when the plate is excited at the first 4 natural frequencies. The location of the bridges is flagged by the red circles. It is then interesting to compare the right hand side of the plate (without bridge) with the left hand side (with 2 bridges).

It appears clearly that the bridges affect locally the elastomer shear deformation. When a bridge is located in a zone of small deformation, its influence on modal damping remains small. In other words, a bridge located in an area where the elastomer is subjected to small shear deformation (blue areas in Figure 25) corresponds to a non significant factor.

\subsection{Identification of the optimal configuration}

\begin{tabular}{|c|c|c|c|c|c|c|c|c|c|c|}
\hline Factor & A & B & C & D & $E$ & $\mathrm{~F}$ & G & $\mathrm{H}$ & J & $\mathrm{K}$ \\
\hline Mode 1 & -2.45 & -0.69 & -1.04 & -3.87 & -0.83 & -0.31 & -0.53 & -0.72 & -4.73 & -1.66 \\
\hline Mode 2 & -5.49 & 0 & -4.63 & 0 & -5.9 & -5.9 & -6.42 & -6.23 & 0 & -6.2 \\
\hline Mode 3 & -5.23 & -0.18 & -6.34 & 0 & -7.71 & 0 & -0.44 & -7.66 & 0 & -6.51 \\
\hline Mode 4 & -8.3 & -22.68 & -3.73 & -0.61 & -9.22 & -0.07 & -4.11 & -11.37 & -18.6 & -0.76 \\
\hline Factor & $\mathrm{AA}$ & $A B$ & $A C$ & $A D$ & $\mathrm{AE}$ & $\mathrm{AF}$ & $A G$ & $\mathrm{AH}$ & AJ & AK \\
\hline Mode 1 & 0.578 & 0 & -1.29 & -2.36 & -1.58 & 0 & 0 & -1.48 & -2.6 & -1.16 \\
\hline Mode 2 & 1.28 & 0 & -2.04 & 0 & -1.49 & -1.45 & -1.14 & -1.7 & 0 & -1.51 \\
\hline Mode 3 & 1.5 & -1 & -4 & -0.73 & -3.4 & 0 & 0 & -3.3 & -0.95 & -3.7 \\
\hline Mode 4 & 3 & -6.48 & 0 & 0 & 0 & -3.54 & 0 & 0 & -11.46 & -3.23 \\
\hline
\end{tabular}

Once the polynomial functions able to predict both the plate deflection and modal damping values have been derived, the cost function is studied as the response of the DOE. The same approach is adopted and a polynomial model is derived from finite element results to predict the cost

Table 18. Coefficients of the 4 polynomial forms derived to predict modal damping values. 


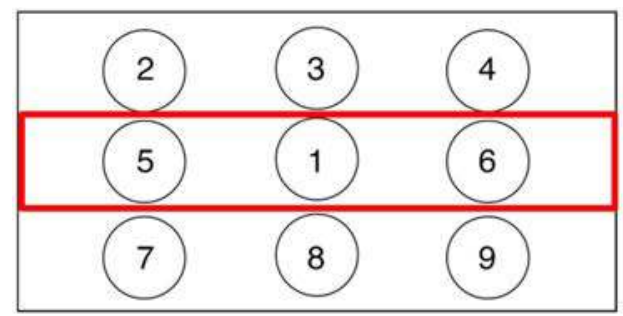

(a) $1^{\text {st }}$ Mode

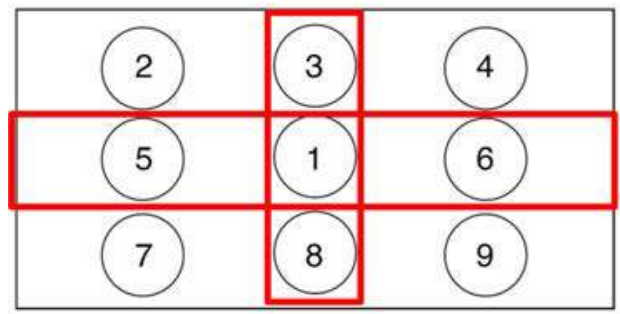

(c) $3^{\text {rd }}$ Mode

Figure 24. Non significant bridges location regarding the modal damping.

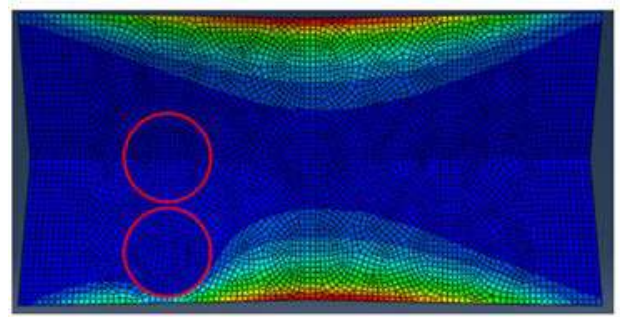

(a) $1^{\text {st }}$ Mode

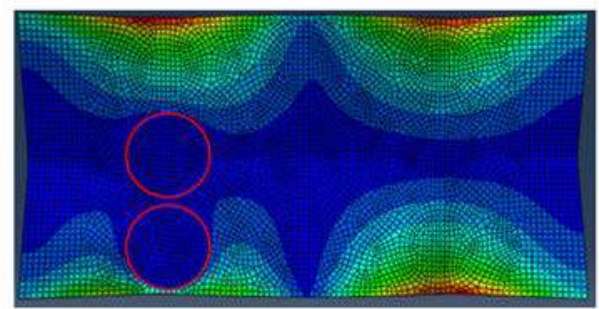

(c) $3^{\text {rd }}$ Mode

Figure 25. Shear strain for the first 4 studied modes.

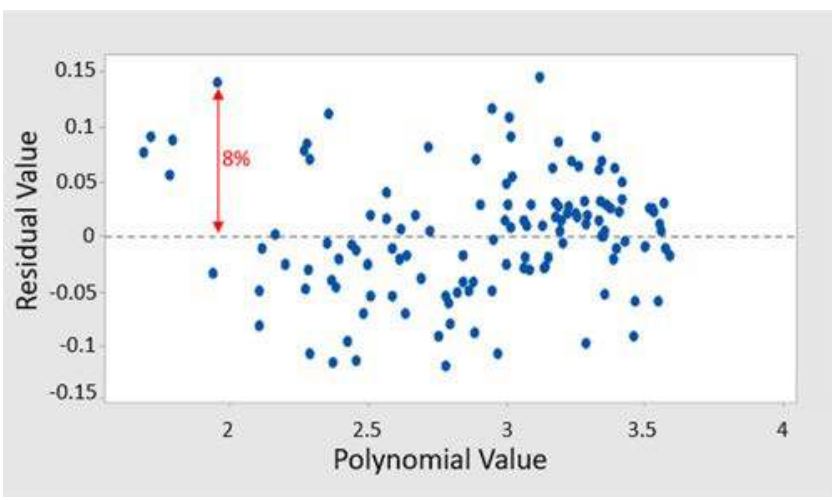

Figure 26. DOE for the cost function: residual vs polynomial values.

function. Related coefficients are also listed in Table 18 . Keeping only the significant factors allows to obtain a prediction capacity of $97 \%$. The quality of the prediction is also

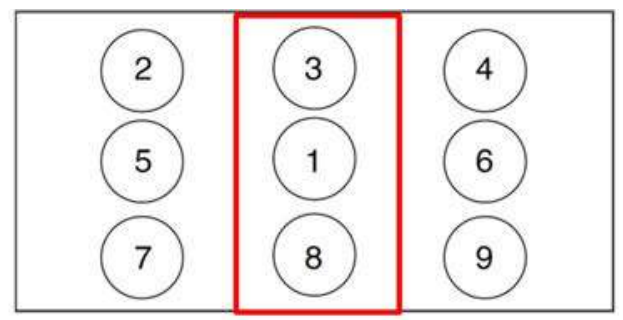

(b) $2^{\text {nd }}$ Mode

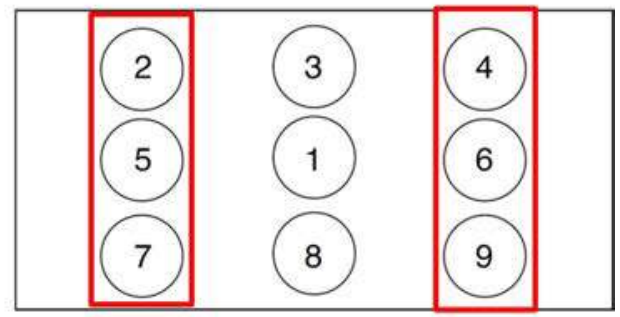

(d) $4^{\text {th }}$ Mode

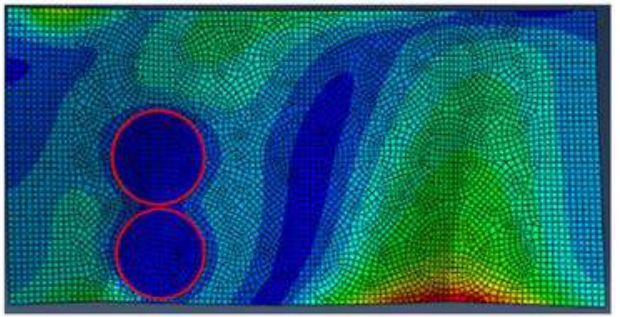

(b) $2^{\text {nd }}$ Mode

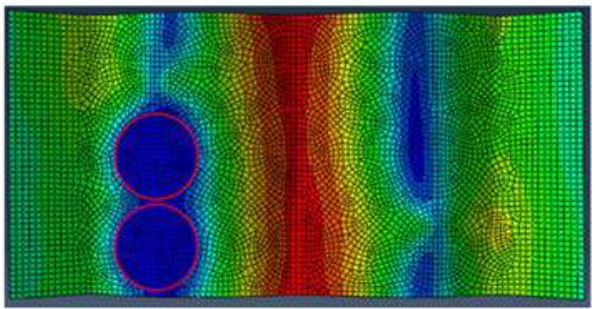

(d) $4^{\text {th }}$ Mode

illustrated by the residual vs polynomial value chart displayed in Figure 26. Resulting gaps between polynomial and numerical values do not exceed $8 \%$. It is worth to note that we could have used the values given by the modal damping predictive polynomials to estimate the cost function but doing this would have accumulate prediction uncertainties and lead to a worse prediction.

To identify the optimal bridge configuration, the predictive polynomial model is then used to calculate the cost function value related to the 2048 configurations. In the same way, the predictive model of the plate deflection (Eq. (13)) is run to identify the configurations that satisfy the stiffness constrain. Considering that for the plate deflection the maximum gap between predicted and explicitly calculated results is equal to $15 \%$, the stiffness ratio to be raised for satisfying the constrain becomes $50 \% \times 1,15=57.5 \%$. The 257 configurations that satisfy this criterion are surrounded by a red 


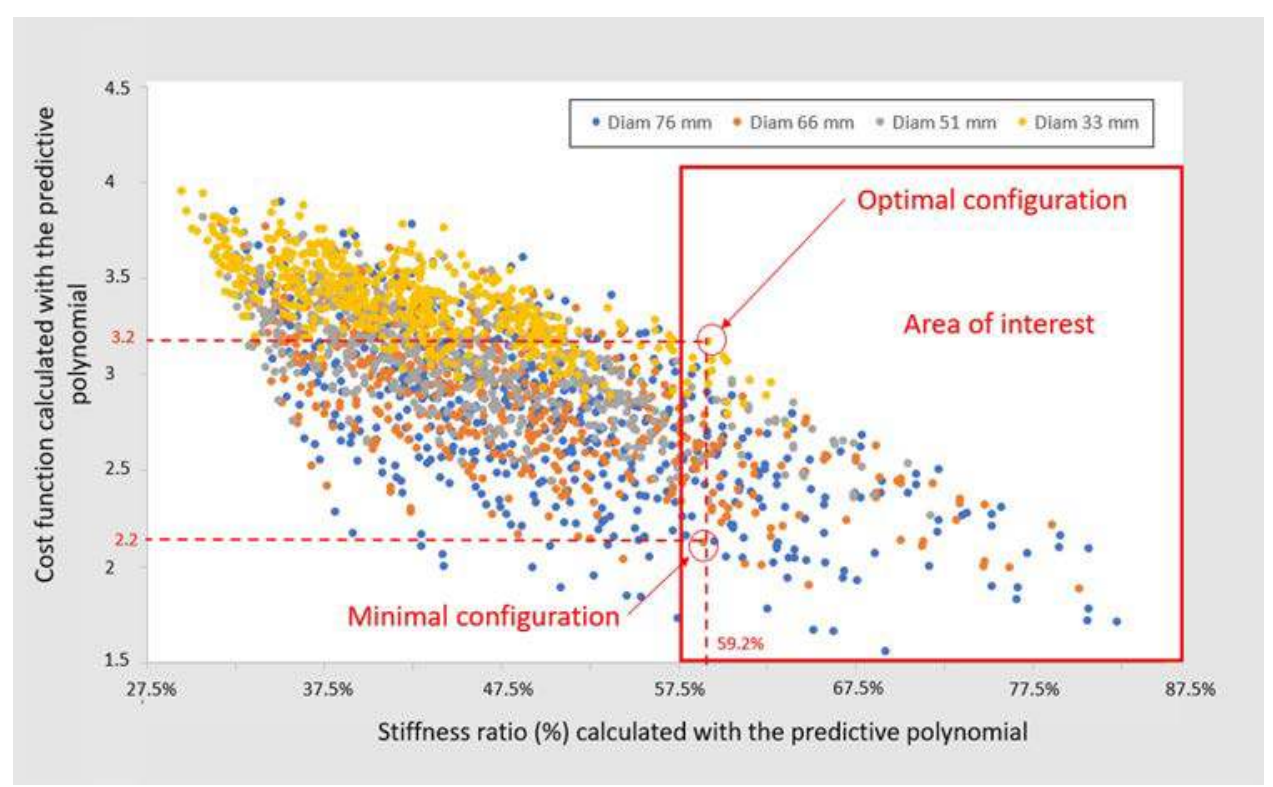

Figure 27. Analysis of the 2048 configurations: cost function vs stiffness ratio.

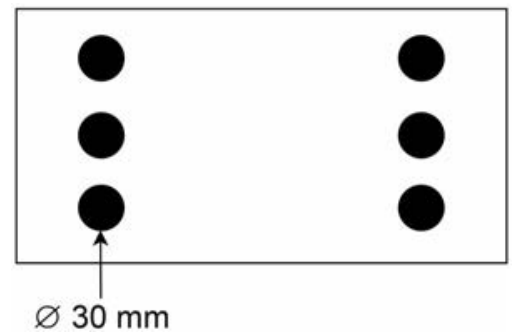

Figure 28. "Bridged" damped plate optimal configuration.

Table 19. Optimal configuration.

\begin{tabular}{lcc}
\hline & Cost function & Stiffness ratio \\
\hline Predicted & 3.2 & $59.2 \%$ \\
Simulated & 3.16 & $61 \%$ \\
\hline
\end{tabular}

line in the Figure 27. It is also observed on this figure that the cost function values calculated for $57.5 \%$ stiffness ratio configurations vary between 1.7 and 3 , which demonstrates the high sensitivity of the modal damping even for configurations with the same stiffness ratio.

Among the 257 configurations satisfying the stiffness criterion, the one with the highest cost function value is considered as the optimal configuration and is flagged by a red circle in Figure 27. It includes 6 bridges with a diameter of $30 \mathrm{~mm}$ and is displayed in Figure 28. Its cost function value and stiffness ratio are given in Table 19, together with those obtained from numerical simulations. A discrepancy of $4 \%$ is observed between predicted and numerical results for the plate deflection and $2 \%$ for the cost function value, which confirms the accuracy of the DOE's prediction.

As Figure 28 bears out, the optimal configuration does not contain any bridge at mid-span. This result was expected regarding the plate stiffness as it has been demonstrated for a beam that a bridge located at mid-span has a small influence on both the stiffness and the damping. However, such result was not so obvious regarding the modal damping associated with the first 4 natural mode shapes. Note that the volume of bridge of this configuration represents $3.3 \%$ of the optimal plate volume, which is in accordance with the results obtained by Robinson et al. (fraction $\leq 5 \%$ ) [3] and Pan et al. (fraction $\leq 7 \%$ ) [4].

Let us now consider the second configuration flagged by a red circle in Figure 27. This so-called minimal configuration has the same stiffness ratio than the optimal one $(K / K C E=59.2 \%)$ but the lowest cost function value $\left(F_{C}=2.2.\right)$. In Figure 29, its dynamic response is compared to the optimal one in frequency ranges that include the first 4 natural frequencies. It is observed that the plate stiffness being the same, an optimized position of the bridges allows to decrease the level of accelerance at the resonance by up to $7 \mathrm{~dB}$. It is thus concluded that the bridge volume fraction alone is not a relevant basis of comparison as the location of the bridges is also a of crucial importance in the process of optimization.

\section{Conclusion}

In this study, static and dynamic bending responses of small carbon-epoxy plates including one frequency-dependent interleaved viscoelastic layer have been investigated both experimentally and numerically.

Different types of plates have been manufactured and tested and the main findings of this experimental work may be summarized as follows:

- Inserting a $1 \mathrm{~mm}$ thick rubber-like film into the laminate has allowed to attenuate by around $21 \mathrm{~dB}$ the plate response amplitude at the resonance but, at the same time, its bending stiffness has been reduced by $65 \%$.

- To mitigate the loss of stiffness, holes have been cut in the viscoelastic layer so as to facilitate the resin through layer penetration during the co-curing process. Resulting bridges created between the carbon-epoxy skins have 


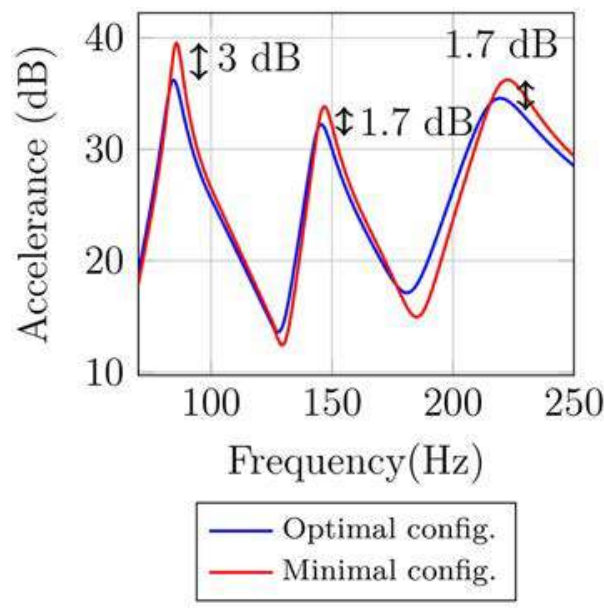

(a) Modes $1-2-3$

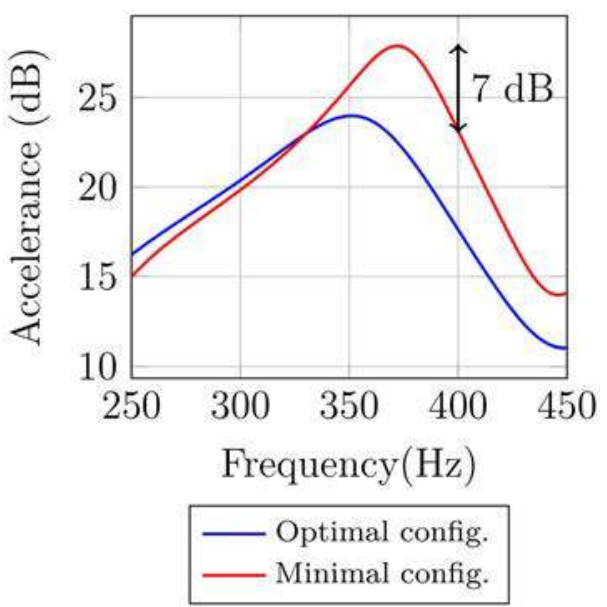

(b) Mode 4

Figure 29. Comparison of the dynamic responses of bridged plate optimal and minimal configurations.

allowed to limit the loss of bending stiffness to 54\% while attenuating by around $19 \mathrm{~dB}$ the response peak amplitude.

- It has been observed that the shape of the created bridges was not as expected. In particular, a micro-graphic analysis has shown that a manual carbon-epoxy prepreg layup does not allow for a satisfactory filling of the holes.

In parallel to this experimental work, finite element models have been developed to simulate the static and dynamic responses of the manufactured plates. While the upper and lower carbon-epoxy skins have been represented by $2 \mathrm{D}$ shell elements, the rubber-like layer has been meshed using 3D solid elements and a visco-hyper-elastic behavior law has been defined. Based on DMA tests performed on the elastomer constituting the viscoelastic layer, frequency dependent shear modulus and damping loss factors have been considered in the simulation of the damped plate forced response.

Finite element models of increasing complexity have thus been set-up and systematically confronted to experimental tests. It has been demonstrated that numerical simulation is able to capture quite accurately the dynamic response of the "bridged" damped plates, given that some uncertainties exist regarding material properties, assembly of the viscoelastic layer with composite skins and fill rate of the holes.

Numerical simulation has then been advantageously used to investigate the influence of the position and volume fraction of one bridge on both the static deflection and dynamic response of a "quasi-2D" simply supported beam. It has been shown that when the bridge comes near a support where the shear deformation of the viscoelastic layer is maximum, the plate bending stiffness increases but, at the same time, the damping is reduced. The main challenge thus consists in finding a good/best compromise between stiffness and damping.

The last part of this work is devoted to the optimization of a "bridged" damped plate. Based on a limited number of numerical simulations, a design of experiments has been developed to optimize the number, the location and the diameter of the bridges with the objective to maximize the modal damping for the 4 first natural modes while keeping a plate stiffness at least equal to half the stiffness of the undamped carbon-epoxy plate. Polynomial functions have been derived to predict both the static plate deflection and a cost function based on the modal damping values related to the first 4 modes. The quality of prediction of these polynomial forms has been checked and all possible bridge configurations have been analyzed to find the optimal one.

\section{Funding}

This research work has been conducted with the financial supports of FEDER - Region Pays de la Loire and ICAM engineering school in the framework of CIPITAP $\mathrm{R} \& \mathrm{D}$ project.

\section{References}

[1] E. E. Ungar, D. Ross, and E. Kerwin, Damping of flexural vibrations by alternate viscoelastic and elastic layers, WADC, 1959.

[2] F. S. Liao, A. C. Su, T. Chien, and J. Hsu, Vibration damping of interleaved carbon fiber-epoxy composite beams, 1994.

[3] M. J. Robinson, and J. B. Kosmatka, Improved damping in VARTM composite structures using perforated viscoelastic layers, J. Compos. Mater., vol. 40, no. 23, pp. 2157-2173, 2006. DOI: $10.1177 / 0021998306062315$.

[4] Lijian, J. Pan Boming, and M. Zhang, A new method for the determination of damping in cocured composite laminates with embedded viscoelastic layer, J. Sound Vib., vol. 319, no. 3-5, pp. 822-831, 2009. DOI: 10.1016/j.jsv.2008.06.044.

[5] L. Pan, and B. Zhang, Damping and mechanical properties of cocured composite laminates with embedded perforate viscoelastic layer, J. Mater. Sci. Technol., vol. 25, no. 4, 2009.

[6] P. P. Hujare, and A. D. Sahasrabudhe, Experimental investigation of damping performance of viscoelastic material using constrained layer damping treatment, Procedia Mater. Sci., vol. 5, pp. 726-733, 2014. DOI: 10.1016/j.mspro.2014.07.321.

[7] R. Moreira, and J. D. Rodrigues, Constrained damping layer treatments: finite element modeling, 2004.

[8] C. M. A. Vasques, and L. C. Cardoso, Vibration and Structural Acoustics Analysis, Springer, New York, 2011. 
[9] D. A. Saravanos, and J. M. Pereira, Effects of interply damping layers on the dynamic characteristics of composite plates, AIAA J., vol. 30, no. 12, pp. 2906-2913, 1992. DOI: 10.2514/3.11636.

[10] H. Wan, Y. Li, and L. Zheng, Vibration and damping analysis of a multilayered composite plate with a viscoelastic midlayer, Shock Vib., vol. 2016, pp. 1-10, 2016. DOI: 10.1155/2016/ 6354915.

[11] C. Xu, M. Z. Wu, and M. Hamdaoui, Mixed integer multiobjective optimization of composite structures with frequencydependent interleaved viscoelastic damping layers, Comput. Struct., vol. 172, pp. 81-92, 2016. DOI: 10.1016/j.compstruc. 2016.05.006

[12] Y. Zhai, and S. Liang, Optimal lay-ups to maximize loss factor of cross-ply composite plate, Compos. Struct., vol. 168, pp. 597-607, 2017. DOI: 10.1016/j.compstruct.2017.01.019.

[13] B. Jean-Marie, Composite Materials, Springer, New York, 1999.

[14] E. Carrera, Historical review of Zig-Zag theories for multilayered plates and shells, Applied Mechanics Reviews., vol. 56, no. 3, pp. 287-308, 2003. DOI: 10.1115/1.1557614.

[15] H. Hu, S. Belouettar, M. Potier-Ferry, and E. M. Daya, Review and assessment of various theories for modeling sandwich composites, Compos. Struct., vol. 84, no. 3, pp. 282-292, 2008. DOI: 10.1016/j.compstruct.2007.08.007.

[16] Y. Koutsawa, and E. M. Daya, Static and free vibration analysis of laminated glass beam on viscoelastic supports, Int. J. Solids Struct., vol. 44, no. 25-26, pp. 8735-8750, dec 2007. DOI: 10. 1016/j.ijsolstr.2007.07.009.

[17] S.-H. Schulze, M. Pander, K. Naumenko, and H. Altenbach, Analysis of laminated glass beams for photovoltaic applications, Int. J. Solids Struct., vol. 49, no. 15-16, pp. 2027-2036, 2012. DOI: $10.1016 /$ j.ijsolstr.2012.03.028.

[18] K. Naumenko, and V. A. Eremeyev, A layer-wise theory for laminated glass and photovoltaic panels, Compos. Struct., vol. 112, pp. 283-291, 2014. DOI: 10.1016/j.compstruct.2014.02.009.
[19] C. Boutin, and K. Viverge, Generalized plate model for highly contrasted laminates, Eur. J. Mech., A/Solids, vol. 55, pp. 149-166, 2016. DOI: 10.1016/j.euromechsol.2015.08.008.

[20] M. V. Donadon, S. F. M. de Almeida, M. A. Arbelo, and A. R. de Faria, A three-dimensional ply failure model for composite structures, Int. J. Aerosp. Eng., vol. 2009, pp. 1-22, 2009. DOI: $10.1155 / 2009 / 486063$.

[21] J. C. Snowdon, Vibration and Shock in Damped Mechanical Systems, Wiley, New York, 1968.

[22] M. L. Williams, R. F. Landel, and J. D. Ferry, The temperature dependence of relaxation mechanisms in amorphous polymers and other glass-forming liquids, J. Am. Chem. Soc., vol. 77, no. 14, pp. 3701-3707, 1955. DOI: 10.1021/ja01619a008.

[23] J. D. Ferry, Viscoelastic Properties of Polymers, Wiley, Hoboken, 1980.

[24] D. J. Ewins, Modal Testing: Theory and Practice, Wiley, Hoboken, 1984.

[25] Dassault Systèmes, Abaqus Theory Manual v6.7, 2007.

[26] N. O. Myklestad, The concept of complex damping, J. Appl. Mech., vol. 19, pp. 284-286, 1952.

[27] C. W. Bert, Material damping: an introductory review of mathematic measures and experimental technique, J. Sound Vib. vol. 29, no. 2, pp. 129-153, 1973. DOI: 10.1016/S0022460X(73)80131-2.

[28] M. Hamdaoui, G. Robin, M. Jrad, and E. M. Daya, Optimal design of frequency dependent three-layered rectangular composite beams for low mass and high damping, Compos. Struct., vol. 120, pp. 174-182, 2015. DOI: 10.1016/j.compstruct.2014.09. 062.

[29] J. S. Moita, A. L. Araújo, C. M. Mota Soares, and C. A. Mota Soares, Finite element model for damping optimization of viscoelastic sandwich structures, Adv. Eng. Softw., vol. 66, pp. 34-39, 2013. DOI: 10.1016/j.advengsoft.2012.10.002.

[30] B. Daniel, T. Yves, and G.-T. Sandrine, Plans d'expériences: construction et analyse, Lavoisier, 1995. 